OPEN ACCESS

Edited by:

Markus J. Tamás,

University of Gothenburg, Sweden

Reviewed by:

B. P. Rosen,

Florida International University Herbert Wertheim College of Medicine, USA

Eric Beitz,

University of Kiel, Germany Neena Goyal,

Central Drug Research Institute (CSIR), India

${ }^{*}$ Correspondence:

Frédéric Frézard frezard@icb.ufmg.br

Specialty section:

This article was submitted to

Cellular Biochemistry,

a section of the journal

Frontiers in Cell and Developmental

Biology

Received: 17 December 2016 Accepted: 07 March 2017

Published: 24 March 2017

Citation:

Reis PG, Monte-Neto RL, Melo MN and Frézard F (2017) Biophysical and

Pharmacological Characterization of

Energy-Dependent Efflux of Sb in Laboratory-Selected Resistant Strains

of Leishmania Niannia) Subgenus.

Front. Cell Dev. Biol. 5:24

doi: 10.3389/fcell.2017.00024

\section{Biophysical and Pharmacological Characterization of Energy-Dependent Efflux of Sb in Laboratory-Selected Resistant Strains of Leishmania (Viannia) Subgenus}

Priscila G. dos Reis ${ }^{1,2}$, Rubens L. do Monte-Neto ${ }^{3}$, Maria N. Melo ${ }^{4}$ and Frédéric Frézard ${ }^{1 *}$

1 Departamento de Fisiologia e Biofísica, Instituto de Ciências Biológicas, Universidade Federal de Minas Gerais, Belo Horizonte, Brazil, ${ }^{2}$ Departamento de Farmácia/Ensino e Pesquisa, Hospital João XXIII - Fundação Hospitalar do Estado de Minas Gerais, Belo Horizonte, Brazil, ${ }^{3}$ Laboratório de Parasitologia Celular e Molecular, Centro de Pesquisas René Rachou - CPqRR/FIOCRUZ, Belo Horizonte, Brazil, ${ }^{4}$ Departamento de Parasitologia, Instituto de Ciências Biológicas, Universidade Federal de Minas Gerais, Belo Horizonte, Brazil

The growing resistance of leishmaniasis to first-line drugs like antimonials in some regions limits the control of this parasitic disease. The precise mechanisms involved in Leishmania antimony resistance are still subject to debate. The reduction of intracellular $\mathrm{Sb}^{\mathrm{III}}$ accumulation is a common change observed in both laboratory-selected and field isolated resistant Leishmania strains, but the exact transport pathways involved in antimony resistance have not yet been elucidated. In order to functionally characterize the antimony transport routes responsible for resistance, we performed systematic transport studies of $\mathrm{Sb}^{\mathrm{III}}$ in wild-type and resistant strains of L. (Viannia) guyanensis and L. (V.) braziliensis. Those include influx and efflux assays and the influence of $A B C$ transporters and metabolism inhibitors: prochlorperazine, probenecid, verapamil, BSO, and sodium azide. The mRNA levels of genes associated with antimony resistance (MRPA, GSH1, $O D C, A Q P 1, A B C / 4$, and $A R M 58)$ were also investigated in addition to intracellular thiol levels. A strong reduction of $\mathrm{Sb}$ influx was observed in $L$. guyanensis resistant mutant (LgSbR), but not in L. braziliensis (LbSbR). Both mutants showed increased energy-dependent efflux of $\mathrm{Sb}^{\mathrm{III}}$, when compared to their respective parental strains. In LgSbR, BSO and prochlorperazine inhibited antimony efflux and resistance was associated with increased MRPA and GSH1 mRNA levels, while in LbSbR antimony efflux was inhibited by probenicid and prochlorperazine in absence of resistance-associated gene modulation. Intracellular thiol levels were increased in both Sb-resistant mutants. An energy-dependent Sblll efflux pathway sensitive to prochlorperazine was clearly evidenced in both Sb-resistant mutants. In conclusion, the present study allowed the biophysical and pharmacological characterization of energy-dependent $\mathrm{Sb}$ efflux 
pathway apparently independent of MRPA, ABCl4, and ARM58 upregulation, in

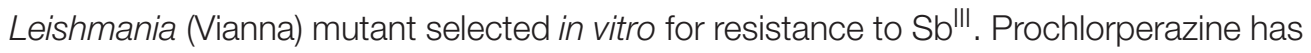
also been identified as an effective chemosensitizer in both Sb resistant mutants, which acts through inhibition of the active efflux of Sb.

Keywords: Leishmania, Viannia, antimony, resistance, chemosensitizer, ABC transporter, efflux, influx

\section{INTRODUCTION}

Protozoan parasites belonging to Leishmania genus are the causative agents of leishmaniasis that produces a wide spectrum of clinical disease in humans ranging from self-healing cutaneous (CL) and mucocutaneous (MCL) lesions to fatal visceral (VL) infection, if not treated (Murray et al., 2005). The disease is a public health concern, endemic in 98 countries reaching up to 1.2 million new cases annually and affecting mainly poor and marginalized populations (Alvar et al., 2012). In the New World, Leishmania (Viannia) braziliensis and Leishmania (Viannia) guyanensis cause cutaneous and mucocutaneous leishmaniasis (MCL) form of the disease (Marzochi and Marzochi, 1994; Murray et al., 2005).

The pentavalent antimony $\left(\mathrm{Sb}^{\mathrm{V}}\right)$ derivatives, sodium stibogluconate $\left(\right.$ Pentostam ${ }^{\circledR}$ and meglumine antimoniate (Glucantime ${ }^{\circledR}$ ), have been used in the treatment of the majority of cases of leishmaniasis for almost 70 years worldwide. Those are considered as prodrugs that are activated through reduction of $\mathrm{Sb}^{\mathrm{V}}$ to $\mathrm{Sb}^{\mathrm{III}}$ (Frézard et al., 2009). Currently, these drugs have two main limitations. First, side effects are frequent and can be fatal. Second, parasite resistance is emerging in some endemic areas, causing an increase in treatment failure (Lira et al., 1999; Hadighi et al., 2006) with major incidence in India, where $65 \%$ of patients are refractories to treatment (Perry et al., 2011).

Studies concerning experimental resistance to antimony in Leishmania indicate that several mechanisms may occur, even concomitantly in the same parasite (Ouellette et al., 2004; Decuypere et al., 2005, 2012; Croft et al., 2006; Mukherjee et al., 2007; Do Monte-Neto et al., 2011; Kumar et al., 2012; Berg et al., 2013; Kazemi-Rad et al., 2013; Cheng and Sun, 2014). The resistance to $\mathrm{Sb}$ in Leishmania usually involves a reduction in the intracellular drug accumulation (Callahan et al., 1994; Dey et al., 1994; Brochu et al., 2003). The upregulation of the $\mathrm{ABC}$ transporter multidrug resistance-associated protein $\mathrm{A}$ (MRPA), identified in intracellular vesicular membranes, is a common change observed in both field isolates and laboratoryselected Leishmania resistant strains (Papadopoulou et al., 1994; Legaré et al., 2001; Decuypere et al., 2005; Mukherjee et al., 2007; Moreira et al., 2013). In some resistant mutants, including the L. guyanensis strain studied here, $\mathrm{Sb}^{\mathrm{III}}$ entry was found to be reduced through either down regulation (Marquis et al., 2005), deletion or a point mutation (Monte-Neto et al., 2015) of the aquaglyceroporin 1 (AQP1) gene. In a recent review, Frézard et al. (2014) pointed out that attempts to characterize the transport pathways of $\mathrm{Sb}^{\mathrm{III}}$ in resistant strains overexpressing the MRPA transporter showed apparently conflicting results, with either increased efflux (Dey et al., 1994) or decreased influx (Callahan et al., 1994) and that other means of transport, besides the sequestration of $\mathrm{Sb}$ in intracellular vesicles, may contribute to the resistance of Leishmania to Sb, such as the efflux of Sb ${ }^{\mathrm{III}}$ by a transporter yet to be identified. Recently, three different membrane proteins were proposed for their putative involvement in $\mathrm{Sb}^{\mathrm{III}}$ efflux in resistant Leishmania parasites. Manzano et al. (2013) and Perea et al. (2016) identified two distinct ABC transporters in L. major capable of promoting $\mathrm{Sb}^{\mathrm{III}}$ and thiol efflux, thereby conferring resistance to antimonials. One of these transporters is a member of ABCI subfamily (LABCI4) and the other one is the ABC protein LABCG2. Both transporters were found to be partially located in the plasma membrane and it was hypothesized that they may confer Sb resistance by sequestering metal-thiol conjugates within vesicles and through further exocytosis by means of the parasite's flagellar pocket. Another membrane protein called ARM58 (antimony resistance marker of $58 \mathrm{kDa}$ ), when overexpressed in L. braziliensis (Nühs et al., 2013) and L. infantum (Schäfer et al., 2014), also promoted resistance to $\mathrm{Sb}$ through reduced drug accumulation and presumably increased efflux of thiol-Sb conjugate. Interestingly, ARM58 was found to be localized near the flagellar pocket hints but, contrary to LABCG2 and LABCl4, it did not seem to mediate energy-dependent transport activity. Indeed, ARM58 is part of a subtelomeric cluster comprising the neighboring genes ARM56 and HSP23, which confers antimony resistance by inducing exosome-mediated secretion (Tejera Nevado et al., 2016). Using a new approach called Cos-Seq-that combines functional cloning and massive next-generation sequencing, Gazanion et al. (2016) have confirmed the up-regulation of ARM58 in laboratoryselected antimony-resistant L. infantum (Gazanion et al., 2016).

Although the mechanisms of Leishmania resistance to $\mathrm{Sb}$ has been extensively studied from the molecular point of view, systematic functional studies involving biophysical and pharmacological approaches to characterize the precise transport pathways of Sb are scarce. In this context, the present work aimed to characterize the transport routes of $\mathrm{Sb}$ in L. braziliensis and L. guyanensis strains selected for their resistance to Sb ${ }^{\mathrm{III}}$ (LbSbR and LgSbR), by using systematic transport kinetic analysis and investigating the effect of $\mathrm{ABC}$ transporter inhibitors on the cytotoxicity, uptake and efflux of Sb.

\section{MATERIALS AND METHODS Chemicals}

Probenecid, prochlorperazine, verapamil, potassium antimonyl tartrate hydrate, kanamycin, L-buthionine-(SR)-sulfoximine (BSO), sodium azide $\left(\mathrm{NaN}_{3}\right)$, HEPES, biopterin, ampicillin, Lglutamine and hemin were obtained from Sigma-Aldrich (St Louis, USA). Nitric acid (65\%) was obtained from Merck Brasil (Rio de Janeiro, RJ, Brazil). 


\section{Leishmania Strains and Sb ${ }^{\text {III }}$ Sensitivity Assay}

Promastigote forms of two different New World Leishmania species: Leishmania (Viannia) guyanensis (MHOM/BR/1975/M4147) and Leishmania (Viannia) braziliensis (MHOM/BR/1975/M2904) were used. Parasites of both strains were selected in vitro for resistance to $\mathrm{Sb}^{\mathrm{III}}$ as previously described (Roberts and Rainey, 1993; Moreira et al., 2013). Promastigotes were exposed to increasing $\mathrm{Sb}^{\mathrm{III}}$ concentrations up to $650 \mu \mathrm{M}$ (L. guyanensis) and $330 \mu \mathrm{M}$ (L. braziliensis) in $25 \mathrm{~cm}^{2}$ flasks containing $5 \mathrm{~mL}$ of minimum essential culture medium ( $\alpha$-MEM) (Gibco, Invitrogen, NY, USA). The selected parasite strains (L. braziliensis $\mathrm{Sb}^{\mathrm{III}} 330.2$ and $L$. guyanensis $\mathrm{Sb}^{\mathrm{III}} 650.4$ ) were maintained in $\alpha$-MEM, supplemented with $10 \%(\mathrm{v} / \mathrm{v})$ heat-inactivated fetal calf serum (Cultilab, Brasil), $100 \mu \mathrm{g} / \mathrm{mL}$ kanamycin, $50 \mu \mathrm{g} / \mathrm{mL}$ ampicillin, $2 \mathrm{mM}$ L-glutamine, $5 \mu \mathrm{g} / \mathrm{mL}$ hemin, $5 \mu \mathrm{M}$ biopterin, $\mathrm{pH} 7.0$ and incubated at $25^{\circ} \mathrm{C}$ in a B.O.D. incubator. As previously described, the resistant mutant L. guyanensis $\mathrm{Sb}^{\mathrm{III}} 650.4$ harbors a single nucleotide polymorphism at AQP1 coding gene that leads to the point mutation G133D at protein level. Functional analysis revealed that this mutation was directly associated with the reduced antimony uptake (Monte-Neto et al., 2015). On the other hand, L. braziliensis resistant mutant presented intact copies of AQP1 as revealed by gene sequencing (Supplementary Figure 1).

To compare the $\mathrm{Sb}^{\mathrm{III}}$ sensitivity of different strains, mid-log phase wild-type and resistant Leishmania promastigotes were inoculated at $10^{6}$ cells $/ \mathrm{mL}$ in $\alpha$-MEM medium in the presence of $\mathrm{Sb}^{\mathrm{III}}$ (as potassium antimonyl tartrate). Biological replicates in the absence of drug were established as control. The cultures were incubated under shaking at $25 \pm 1{ }^{\circ} \mathrm{C}$ for $72 \mathrm{~h}$ and the growth inhibition was determined by measuring the absorbance at $600 \mathrm{~nm}$ using a microplate reader (Organon Teknica Microwell), as previously described (Fumarola et al., 2004). Three independent experiments were carried out. The half-maximal inhibitory concentration $\left(\mathrm{IC}_{50}\right)$ values were calculated based on concentration-response curves applying a sigmoidal doseresponse equation with variable slope carried out using the software GraphPad Prism version 6.0 (GraphPadSoftware Inc., San Diego, CA, USA).

\section{Real Time qRT-PCR}

Total RNA was extracted from $10^{8}$ mid-log phase Leishmania spp. promastigotes using RNeasy Plus mini kit (Qiagen Sciences, Maryland, USA) as described by the manufacturer. First-strand cDNA was synthesized from $2.5 \mu \mathrm{g}$ of total RNA using Oligo dT12-18 and SuperScript II RNase H-Reverse Transcriptase (Invitrogen, Carlsbad, CA, USA) according to the manufacturer protocol. Equal amounts of cDNA were run in triplicate and amplified in $25 \mu \mathrm{L}$ reactions containing 1 x iQ SYBR ${ }^{\circledR}$ Green Supermix (Bio-Rad, Hercules, CA, USA), $100 \mathrm{nM}$ forward and reverse primers and $100 \mathrm{ng}$ of cDNA target. Reactions were carried out using a rotator thermocycler Rotor Gene (RG 3000, Corbett Research, San Francisco, USA). Mixtures were initially incubated at $95^{\circ} \mathrm{C}$ for $5 \mathrm{~min}$ and then cycled 30 times at $95^{\circ}, 60^{\circ}$, and $72^{\circ} \mathrm{C}$ for $15 \mathrm{~s}$. No-template controls were used as recommended. Three technical and biological replicates were established for each reaction. The relative amount of PCR products generated from each primer set was determined based on the cycle threshold $(\mathrm{Ct})$ value and the amplification efficiencies. Data were analyzed using the comparative $2^{-\Delta \Delta C t}$ method. Gene expression levels were normalized to constitutively expressed mRNA encoding glyceraldehyde-3-phosphate dehydrogenase (GAPDH, LbrM.30.2950). The primers for targeted genes: MRPA (LbrM.23.0280), GSH1-that encodes to gammaglutamylcysteine synthetase ( $\gamma$ GCS-LbrM.14.0880), ODC (LbrM.12.0300), AQP1 (LbrM.31.0020), ABCI4 (LbrM.33.3540), ARM58 (LbrM.20.0210), and internal gene expression control GAPDH were designed using PrimerQuest ${ }^{\circledR}$ (https://www. idtdna.com/Primerquest/Home/Index). Primer sequences are listed in Table 1.

\section{Total Intracellular Thiol Measurement}

Total intracellular thiols were derivatized from deproteinized cell extracts and separated by high-performance liquid chromatography (HPLC) as previously described (Fairlamb et al., 1987; Mukhopadhyay et al., 1996). Briefly, $10 \mathrm{~mL}$ of $\mathrm{Sb}$-free logarithmic phase Leishmania promastigote cultures were haversted at $0.3-0.4$ absorbance $(600 \mathrm{~nm})$; washed twice in HEPES/ $\mathrm{NaCl}(21 \mathrm{mM}$ HEPES; $137 \mathrm{mM} \mathrm{NaCl} ; 5 \mathrm{mM} \mathrm{KCl}$; $0.7 \mathrm{mM} \mathrm{Na}_{2} \mathrm{HPO}_{4} ; 6 \mathrm{mM}$ Glucose; $\mathrm{pH}$ 7) and resuspended in HEPES/EDTA (50 mM HEPES; 5 mM EDTA; 1 mM DTT pH 8). At this step, $10 \mu \mathrm{L}$ were separated for protein dosage by bradford method (Bradford, 1976). Protected from light, $100 \mu \mathrm{L}$ of $2 \mathrm{mM}$ monobromobimane (mBBr) (Invitrogen, Carlsbad, CA, USA) were added to the samples, mixed and incubated at $70^{\circ} \mathrm{C}$ for 3

TABLE 1 | Chosen target genes and their primer pairs used for RT-qPCR.

\begin{tabular}{|c|c|c|}
\hline Gene product (ID) & Sequence of forward and reverse primers & $\begin{array}{l}\text { Product } \\
\text { size (bp) }\end{array}$ \\
\hline \multicolumn{3}{|l|}{ MRPA } \\
\hline \multirow[t]{2}{*}{ LbrM.23.0280 } & 5'TGTCCACCTGGCCAATGTAGTCTT3' & 125 \\
\hline & 5'TCGGAAAGACAACCTCCGGCTTA3' & \\
\hline \multicolumn{3}{|l|}{ GSH1 } \\
\hline \multirow[t]{2}{*}{ LbrM.14.0880 } & 5'GAACACGGCTGATCAGTACAA3' & 118 \\
\hline & 5'AAGGTTAGCGTGCTCAAGTC3' & \\
\hline \multicolumn{3}{|l|}{$O D C$} \\
\hline \multirow[t]{2}{*}{ LbrM.12.0300 } & 5'GTACATCGAGAAGGGTGTGAAG3' & 127 \\
\hline & 5'GCCGAGGTCAATGATGTAGAA3' & \\
\hline \multicolumn{3}{|l|}{ AQP1 } \\
\hline \multirow[t]{2}{*}{ LbrM.31.0020 } & 5'TCTCGCCATCAACGATAACC3' & 126 \\
\hline & 5'CGTGTAGGGTTGAGAGCATATC3' & \\
\hline \multicolumn{3}{|l|}{$A B C I 4$} \\
\hline \multirow[t]{2}{*}{ LbrM.33.3540 } & 5'CTGTAGACGAAGCGGGTATTT3' & 135 \\
\hline & 5'CTAGGCGATGAGACACCATAAC3' & \\
\hline \multicolumn{3}{|l|}{ ARM58 } \\
\hline \multirow[t]{2}{*}{ LbrM.20.0210 } & 5'CCCAAGGGCTTTCACCTAAA3' & 103 \\
\hline & 5'AGCGGTAGATCTTGTCGTATTG3' & \\
\hline
\end{tabular}


min. Trichloroacetic acid (Fischer Chemical, Atlanta, GA, USA) $(200 \mu \mathrm{L}$ at $25 \%)$ were added to the mixture, and the extract was kept at $80^{\circ} \mathrm{C}$ for at least, $1 \mathrm{~h}$ followed by low temperature $\left(4^{\circ} \mathrm{C}\right)$ centrifugation at top speed (microcentrifuge) for $20 \mathrm{~min}$. Supernatants were filtered in $0.45-\mu \mathrm{m}$ filters (Acrodisc Pall, Life Sciences, East Hills, NY, USA) and thiols separated using the liquid chromatograph Shimadzu SCL 10A. Samples were analyzed using a reverse phase column Vydac C18 eluted in methanol 0-100\%/acetic acid (25\%) gradient $\mathrm{pH} 3.5$. Standard solutions of $\mathrm{mBBr}$-derivatized cysteine (Cys), glutathione (GSH) and trypanothione (TSH) were previously established as calibration curve. Thiols were indirectly measured by $\mathrm{mBBR}$ fluorescence at 360 and $450 \mathrm{~nm}$ of excitation and emission, respectively, using a coupled fluorescence detector (Shimadzu RF-10Axl).

\section{Sb Uptake}

Before performing the assays, $\mathrm{Sb}^{\mathrm{III}}$-resistant Leishmania spp. lines were maintained for at least two passages in $\alpha$-MEM medium in the absence of $\mathrm{Sb}^{\mathrm{III}}$, in order to eliminate the residual drug.

The Sb uptake kinetic and influx assays were based on previously described protocols (Roberts and Rainey, 1993; Moreira et al., 2013). Briefly, mid-log phase wild-type and resistant Leishmania promastigotes were washed twice in Hepes/Glucose (HG) buffer (20 mM HEPES, $0.15 \mathrm{M} \mathrm{NaCl}, 10$ $\mathrm{mM}$ glucose, $\mathrm{pH}$ 7.2) and suspended in this buffer at a density of $10^{8}$ cells $/ \mathrm{mL}$.

In the uptake kinetic assay, cells were incubated in the presence of $\mathrm{Sb}^{\mathrm{III}}$ at $540 \mu \mathrm{M}$. In different time points, $1 \mathrm{~mL}$ of the cell suspension was harvested and immediately centrifuged at $3,000 \times \mathrm{g}$ for $5 \mathrm{~min}$ at $4^{\circ} \mathrm{C}$ and the pellet was washed twice with HG buffer under the same conditions. The pellet was then resuspended in $100 \mu \mathrm{L}$ HG buffer. A $10-\mu \mathrm{L}$ aliquot of each sample was used for parasite quantification and viability evaluation and the remaining volume $(90 \mu \mathrm{L})$ was submitted to digestion in nitric acid (65\%). Cell viability was confirmed from the promastigote motility and trypan blue exclusion assay (Freshney, 1994). More than 90\% of promastigotes showed motility, except those exposed to sodium azide and more than $95 \%$ of cells were considered viable according to trypan blue exclusion. The $\mathrm{Sb}$ concentration was determined by graphite furnace atomic absorption spectroscopy (Perkin Elmer, AAnalyst 600). The signal from a blank (cells without Sb) was used for background subtraction. The analytical method for determination of $\mathrm{Sb}$ was validated and showed suitable levels of precision, accuracy and linearity. The quantification limit of the analytical method was $0.021 \mathrm{nmol} \mathrm{Sb/108}$ promastigotes. The amount of cellular $\mathrm{Sb}$ at the zero time point was equal to $0.044 \pm 0.002 \mathrm{nmol} \mathrm{Sb} / 108$ promastigotes and, thus, close to the quantification limit, indicating that the binding of $\mathrm{Sb}$ to the cell surface is negligible, in agreement with the high hydrophilicity of potassium antimonyl tartrate.

For influx assay, parasites were exposed to $\mathrm{Sb}^{\mathrm{III}}$ for $1 \mathrm{~h}$ at $25^{\circ} \mathrm{C}$, at increasing concentrations $(0 ; 100 ; 250 ; 500 ; 1,000$; 1,$500 ; 2,000 \mu \mathrm{M}$ of $\left.\mathrm{Sb}^{\mathrm{III}}\right)$, in quadruplicates/point. Samples were submitted to the washing procedure mentioned above for removing extracellular $\mathrm{Sb}$ traces. Each influx assay was performed three times. The influx rate was calculated as follows: $\mathrm{Vi}=$ amount of intracellular antimony/(number of cells $\mathrm{x}$ time of uptake). A shorter incubation time could not be used, because of the method quantification limit and loss of accuracy in the determination of the initial rate. Thus, the values determined for initial rate were approximation of the influx rates, especially in the case of WT cells in which Sb uptake was not linear over 1$\mathrm{h}$ time. The Vi-vs-Ce curves were analyzed using the GraphPad Prism 6.0 software to assess whether they best fit with a linear model or the Michaelis-Menten equation as follows:

$$
\mathrm{Vi}=\mathrm{Vi}_{\max } \times \mathrm{Ce} /\left(\mathrm{Ce}+\mathrm{K}_{\mathrm{m}}\right)
$$

where $V_{\max }$ is the maximum influx rate, $\mathrm{K}_{\mathrm{m}}$ is the MichaelisMenten constant and Ce is the extracellular concentration of Sb.

The influx rate constant $\left(\mathrm{k}_{\text {influx }}\right)$ was calculated as:

$$
\mathrm{k}_{\text {influx }}=\mathrm{Vi}_{\max } / \mathrm{K}_{\mathrm{m}}
$$

When no saturation was observed, $\mathrm{k}_{\text {influx }}$ was determined by linear regression, assuming that $\mathrm{Vi}=\mathrm{k}_{\text {influx }} \times \mathrm{Ce}$.

This influx assay was also used to identify the values of $\mathrm{Ce}$ at which the mutant and its parental line exhibited the same intracellular concentration of $\mathrm{Sb}$, to be explored in the efflux protocol.

To evaluate the effect of $\mathrm{ABC}$ transporter inhibitors on $\mathrm{Sb}^{\mathrm{III}}$ uptake, mid-log phase Leishmania spp. promastigotes were first exposed for $24 \mathrm{~h}$ to each of these compounds at nontoxic concentrations ( $8 \mu \mathrm{M}$ verapamil, $4 \mathrm{mM}$ probenecid, $10 \mu \mathrm{M}$ prochlorperazine, $100 \mu \mathrm{M}$ BSO for resistant strains and $8 \mu \mathrm{M}$ verapamil, $4 \mathrm{mM}$ probenecid, $3.5 \mu \mathrm{M}$ prochlorperazine, $100 \mu \mathrm{M}$ BSO for parental strains). The cells were then resuspended in HG buffer at $10^{8}$ cells $/ \mathrm{mL}$ and further exposed to these compounds for $1 \mathrm{~h}$ at $25^{\circ} \mathrm{C}$, in the presence of $1 \mathrm{mM}$ of $\mathrm{Sb}{ }^{\mathrm{III}}$. Samples were washed twice with cold HG buffer to remove external $\mathrm{Sb}$ and allow the measurement of intracellular $\mathrm{Sb}$. We observed that more than $90 \%$ of promastigotes showed motility at the end of the experiment, suggesting that the inhibitors did not act through depletion of intracellular ATP.

When investigating the impact of energy depletion on the uptake of $\mathrm{Sb}^{\mathrm{III}}$, cells were resuspended in the HG buffer without glucose, but in the presence of $10 \mathrm{mM}$ sodium azide. Those were then incubated for $1 \mathrm{~h}$ at $25^{\circ} \mathrm{C}$ in the presence of $1 \mathrm{mM}$ of Sb${ }^{\mathrm{III}}$ and were subsequently processed as described above.

\section{Sb Efflux}

Before performing this assay, $\mathrm{Sb}^{\mathrm{III}}$-resistant Leishmania lines were maintained for at least two passages in $\alpha$-MEM medium in the absence of $\mathrm{Sb}^{\mathrm{III}}$, in order to remove the residual drug. Midlog phase wild-type and resistant Leishmania promastigotes were washed twice with HG buffer and resuspended in it a density of $10^{8}$ cells $/ \mathrm{mL}$. A $1-\mathrm{mL}$ aliquot containing only parasites (blank) was separated and the remaining cells were incubated at $25^{\circ} \mathrm{C}$ with the concentration of $\mathrm{Sb}^{\mathrm{III}}$ pre-established in influx assay so as to obtain the same loading of drug in the resistant strain and its parental cells (L. guyanensis, $100 \mu \mathrm{M}$ for WT and 2,000 $\mu \mathrm{M}$ 
for the mutant; L. braziliensis, $500 \mu \mathrm{M}$ for WT and 2,000 $\mu \mathrm{M}$ for the mutant). After $1 \mathrm{~h}$ incubation, the cells were centrifuged at $3,000 \times \mathrm{g}$ for $5 \mathrm{~min}$ at $4^{\circ} \mathrm{C}$, washed twice and resuspended in $\mathrm{HG}$ buffer at the original cell density followed by incubation at $25^{\circ} \mathrm{C}$. Aliquots of $1 \mathrm{~mL}$ were taken from the parasite suspension at 0,15 , 30,60 , and $120 \mathrm{~min}$. Subsequently, these aliquots and the blanks were treated as described above for the quantification of parasite and intracellular $\mathrm{Sb}$. The signal from blanks was considered as background.

Each efflux assay was performed three times in triplicate. Data were plotted as the percentage of initial intracellular Sb content as a function of time and the half-time of Sb efflux was calculated using mono-exponential decay model. The efflux rate constant $\mathrm{k}_{\mathrm{efflux}}$ was also obtained from the equation:

$$
\mathrm{Ve}=\mathrm{k}_{\text {efflux }} \times \mathrm{Ci}
$$

where $\mathrm{Ve}$ is the initial rate of efflux determined from the tangent of the curve and $\mathrm{Ci}$ is the intracellular concentration of $\mathrm{Sb}$ estimated at time zero using a cell volume of $1.2 \times 10^{-14} \mathrm{~L}$ (Zilberstein and Dwyer, 1984).

To evaluate the interference of $\mathrm{ABC}$ transporter inhibitors on $\mathrm{Sb}$ efflux, the cells were initially loaded for $1 \mathrm{~h}$ at $25^{\circ} \mathrm{C}$ with $1 \mathrm{mM}$ of $\mathrm{Sb}^{\mathrm{III}}$ in $\alpha$-MEM medium. The cells were washed and resuspended in HG buffer at $10^{8}$ cells $/ \mathrm{mL}$. A $1-\mathrm{mL}$ aliquot was immediately removed and processed to determine the initial intracellular amount of $\mathrm{Sb}^{\mathrm{III}}$. The remaining cells were exposed to the inhibitors at non-toxic concentrations $(8 \mu \mathrm{M}$ verapamil, $4 \mathrm{mM}$ probenecid, $10 \mu \mathrm{M}$ prochlorperazine, $100 \mu \mathrm{M}$ BSO, 10 $\mathrm{mM}$ sodium azide in resistant strains and $8 \mu \mathrm{M}$ verapamil, 4 $\mathrm{mM}$ probenecid, $3.5 \mu \mathrm{M}$ prochlorperazine, $100 \mu \mathrm{M}$ BSO, $10 \mathrm{mM}$ sodium azide in parental strains) for $2 \mathrm{~h}$ at $25^{\circ} \mathrm{C}$ under agitation. Only when evaluating the effect of azide, that the buffer did not contain glucose. The cells were subsequently processed as described above to determine the amount of Sb per cell. We observed that more than $90 \%$ of promastigotes showed motility at the end of the experiments when applying verapamil, probenecid, prochlorperazine or BSO, suggesting that these inhibitors did not act through depletion of intracellular ATP.

\section{Antileishmanial Activity of ABC Transporter Inhibitors and Their Role as Chemosensitizer in SbR Leishmania}

First, ABC transporter inhibitors (probenecid, prochlorperazine, verapamil and BSO) were evaluated for their antileishmanial activity against SbR and WT Leishmania spp.. Mid-log phase promastigotes were inoculated at $10^{6}$ cells $/ \mathrm{mL}$ in $\alpha$-MEM medium in the presence of different concentrations of the inhibitors. Biological replicates in the absence of drug were established as control. The cultures were incubated under shaking at $25 \pm 1^{\circ} \mathrm{C}$ for $72 \mathrm{~h}$ and the $\mathrm{IC}_{50}$ s were determined as described above (section Leishmania Strains and $\mathrm{Sb}^{\mathrm{III}}$ Sensitivity Assay). The ability of each inhibitor to sensitize the cells to $\mathrm{Sb}^{\mathrm{III}}$ was evaluated by performing growth inhibition assay as described above, in the presence of a fixed non-toxic concentration of the inhibitor $(8 \mu \mathrm{M}$ verapamil, $4 \mathrm{mM}$ probenecid, $10 \mu \mathrm{M}$ prochlorperazine, $100 \mu \mathrm{M}$ BSO in resistant strains and $8 \mu \mathrm{M}$ verapamil, $4 \mathrm{mM}$ probenecid, $3.5 \mu \mathrm{M}$ prochlorperazine, $100 \mu \mathrm{M}$ $\mathrm{BSO}$ in parental strains). The $\mathrm{IC}_{50}$ values of $\mathrm{Sb}^{\mathrm{III}}$ in presence and absence of inhibitor were compared. All experiments were done at least three times as independent experiments performed in triplicate.

\section{Statistical Analyses}

The $\mathrm{IC}_{50}$ values were calculated by non-linear regression. Data were analyzed by Student's $t$-test or One-way analysis of variance (ANOVA) followed by Bonferroni's multiple comparison test. A $p \leq 0.05$ was considered statistically significant. All analyses were carried out using the software GraphPad Prism version 6.0 (GraphPad Software Inc., La Jolla, CA, USA).

\section{RESULTS}

\section{Sb"ll Sensitivity, mRNA Levels of Resistance Markers and Thiol Levels}

While L. braziliensis and L. guyanensis parental strains presented $\mathrm{IC}_{50}$ of $\mathrm{Sb}^{\mathrm{III}}$ lower than $100 \mu \mathrm{M}$, the resistant mutants suffered little influence of $\mathrm{Sb}^{\mathrm{III}}$ at concentration as high as $600 \mu \mathrm{M}$ (Table 2 See also growth inhibition curves in Supplementary Figure 2).

The mRNA levels of MRPA, GSH1, ODC, AQP1, ABCI4, and ARM58-genes associated with Sb resistance in Leishmania parasites-were investigated. As shown in Figure 1B, increased mRNA levels of MRPA (2-fold) and to a lower extent of GSH1 (1.5-fold) were found in LgSbR mutant, when compared to the parental strain. No differences were observed for ODC or AQP1 mRNA for this mutant (Figure 1). On the other hand, LbSbR mutant did not exhibit any relevant change in mRNA levels of either MRPA, GSH1, AQP1, ABCI4, or ARM58 (Figure 1A). Despite the fact that no significant difference on mRNA levels of thiol biosynthetic enzymes was observed, increased levels of cysteine and glutathione for LgSbR and a higher amount of trypanothione in LbSbR were detected when compared to WT lines (Figure 2).

\section{Kinetics of Sb Uptake and Influx Studies}

Figure 3 shows the kinetics of Sb uptake in L. braziliensis and L. guyanensis SbR mutants in comparison to their parental strains. The results indicate that both mutants exhibited a lower initial rate of Sb influx $\left(3 \times 10^{-12}\right.$ and $0.4 \times 10^{-12}$ nmol.s ${ }^{-1}$.cell ${ }^{-1}$ for L. braziliensis and L. guyanensis, respectively) when compared to their respective susceptible counterparts $\left(7 \times 10^{-12}\right.$ and $5 \times 10^{-12}$ nmol.s ${ }^{-1}$.cell ${ }^{-1}$, for L. braziliensis

TABLE 2 | Half-maximal growth inhibition concentrations $\left(\mathrm{IC}_{50}\right)$ of $\mathrm{Sb}^{\mathrm{III}}$ in Sb-resistant $L$. braziliensis and $L$. guyanensis promastigotes and their respective parental lines and corresponding resistance index.

\begin{tabular}{lccc}
\hline \multirow{2}{*}{ Species } & \multicolumn{2}{c}{$\mathbf{I C}_{\mathbf{5 0}}(\boldsymbol{\mu} \mathbf{M})$} & \multirow{2}{*}{ Resistance index } \\
\cline { 2 - 3 } & Wild type & Resistant & \\
\hline L. N.) braziliensis & $86.1 \pm 1.1$ & $623.7 \pm 44.7$ & 7.2 \\
L. N.) guyanensis & $47.4 \pm 7.8$ & $1167 \pm 1.1$ & 24.6
\end{tabular}



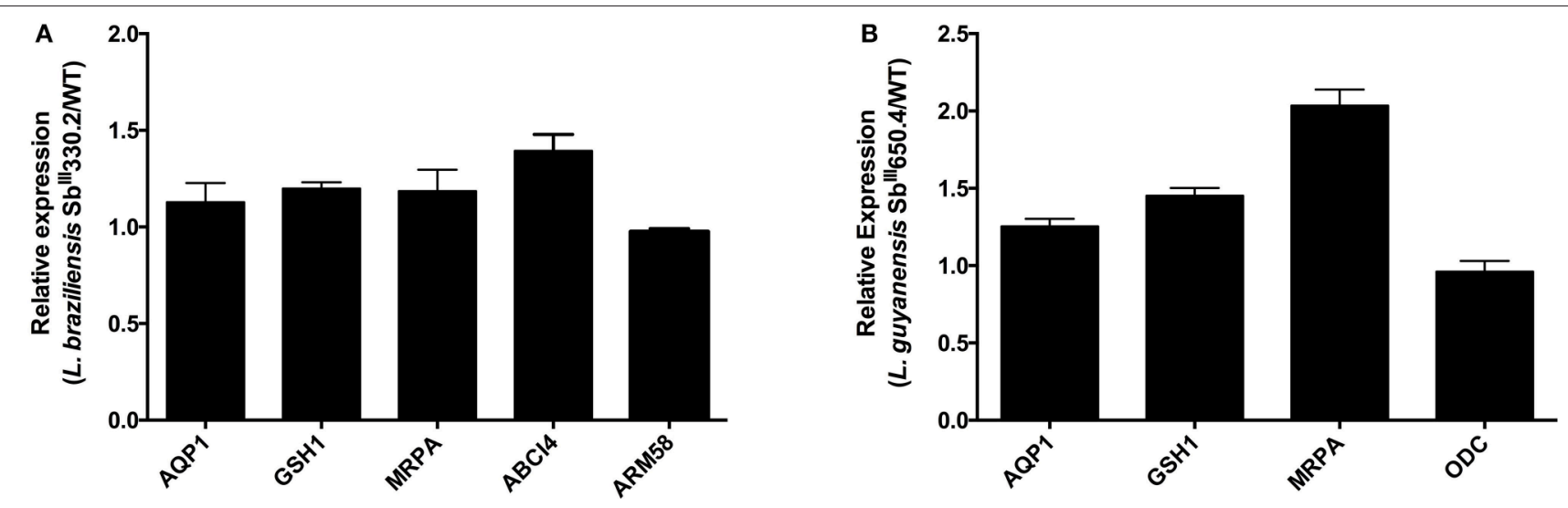

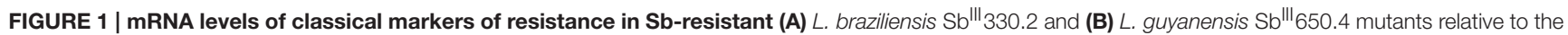
respective WT parental strains. The mRNA levels were determined by real time PCR. (A) mRNA of, AQP1, GSH1, MRPA, ABCl4, and ARM58. (B) mRNA of AQP1, GSH1, MRPA, and ODC. Results are shown as means of three independent experiments performed from three different RNA preparations.

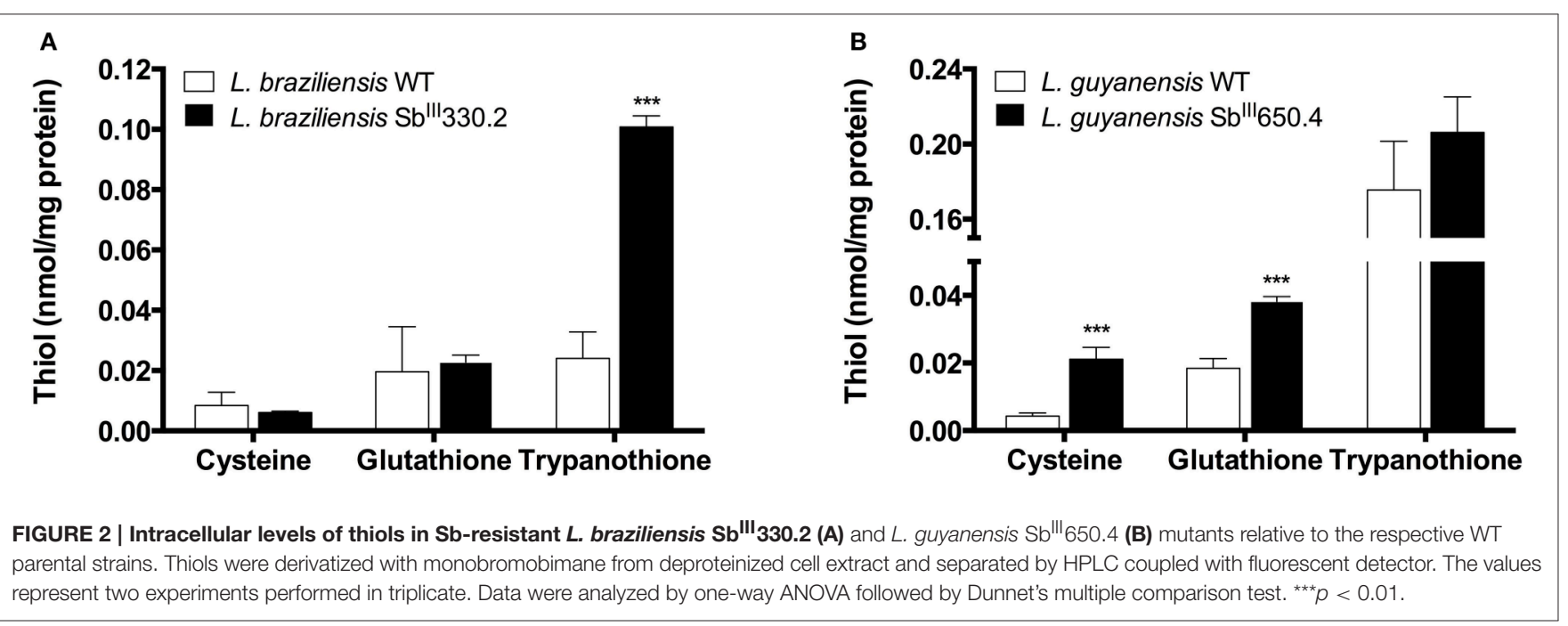

and L. guyanensis, respectively). As illustrated in Figure 4, the determination of the initial rate of Sb influx as a function of the extracellular $\mathrm{Sb}$ concentration showed a saturation at high drug concentration in the case of all strains, except for LgSbR. The kinetics constants of $\mathrm{Sb}$ influx were then calculated according to the Michaelis-Menten model (Table 3). We can infer that the decrease of drug influx contributed to the reduction of drug uptake, mainly in the case of LgSbR.

\section{Kinetics of Sb Efflux}

After loading the mutant and WT promastigotes with a similar amount of $\mathrm{Sb}$ (the initial amounts of $\mathrm{Sb}$ were respectively: 0.50 $\pm 0.018 \mathrm{nmol} / 10^{8}$ cells and $0.53 \pm 0.021 \mathrm{nmol} / 10^{8}$ cells for L. guyanensis WT and mutant; and $2.37 \pm 0.53 \mathrm{nmol} / 10^{8}$ cells and $2.28 \pm 0.61 \mathrm{nmol} / 10^{8}$ cells for L. braziliensis WT and mutant), the cells were washed and resuspended in a drugfree buffer to assess the kinetic of drug release. As shown in Figure 5, the $\mathrm{Sb}$ efflux was faster from the SbR mutants when compared with their WT counterparts. Assuming a monoexponential drug release model, the half-time of drug release was estimated and compared between the different cell lines (Table 4). The efflux of $\mathrm{Sb}$ was found 45 -fold and 21-fold faster in LgSbR and LbSbR, respectively. These data support the model in which the increase of drug efflux strongly contributes to the reduction of drug uptake in both Leishmania mutants.

\section{Effects of the ABC Transporter Inhibitors on Sb Uptake and Efflux in Leishmania spp.}

To further characterize the $\mathrm{Sb}^{\mathrm{III}}$ transport routes involved in the resistance of both L. braziliensis and L. guyanensis Sb-resistant mutants, a pharmacological approach was adopted based on the use of the following classical $\mathrm{ABC}$ transporter inhibitors: verapamil as MDR1-transporter inhibitor (Neal et al., 1989; Valiathan et al., 2006); probenicid as MRP-transporter inhibitor (Courtois et al., 1999; Payen et al., 2000; Mandal et al., 2009); prochlorperazine as MDR1- and MRP-transporter modulator 

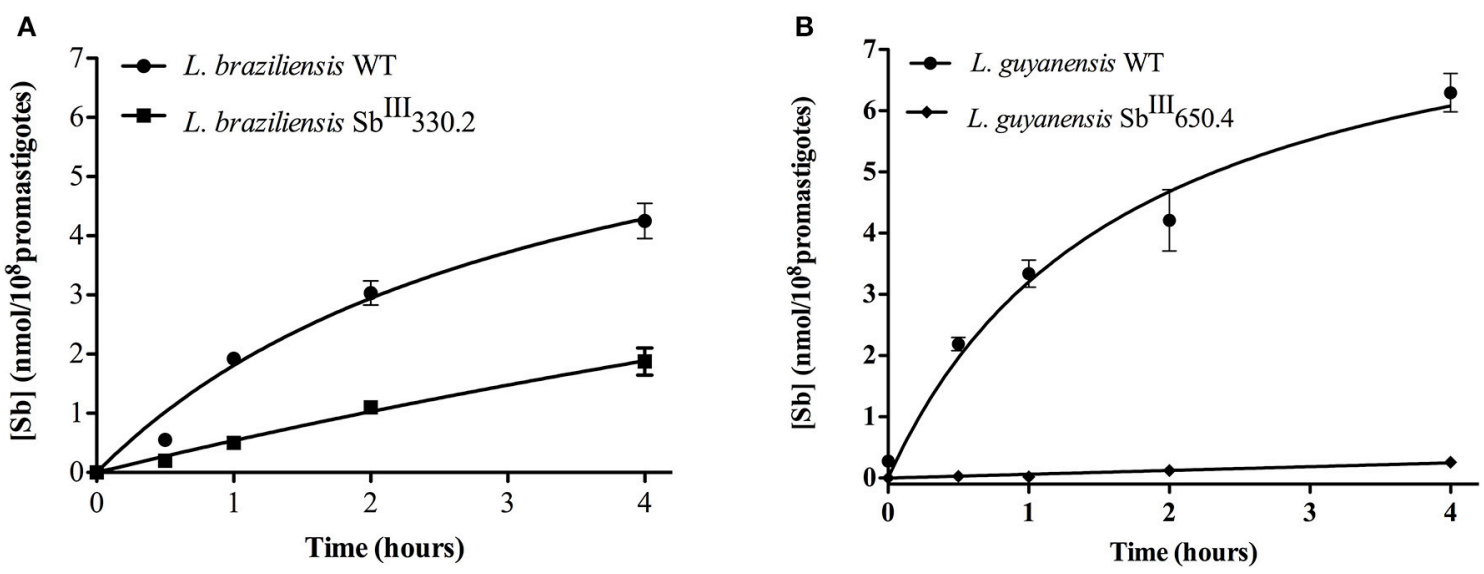

FIGURE 3 | Kinetics of incorporation of Sb ${ }^{\text {III }}$ uptake in WT and Sb ${ }^{\text {III }}$-resistant and L. braziliensis $\mathbf{S b}^{\text {III }} \mathbf{3 3 0 . 2}$ (A) and L. guyanensis Sb ${ }^{\text {III } 650.4 ~(B) ~}$ promastigotes. Cells were incubated with $540 \mu \mathrm{M} \mathrm{Sb} \mathrm{Sll}^{\prime \prime}$ at $25 \pm 1^{\circ} \mathrm{C}$ under agitation shaking in Hepes/NaCl/Glucose buffer. Cells were harvested and washed at different time points for intracellular Sb determination by graphite furnace atomic absorption spectrometry. The values of $\mathrm{Sb}$ content are shown as means $\pm \mathrm{SEM}$ $(n=8)$.
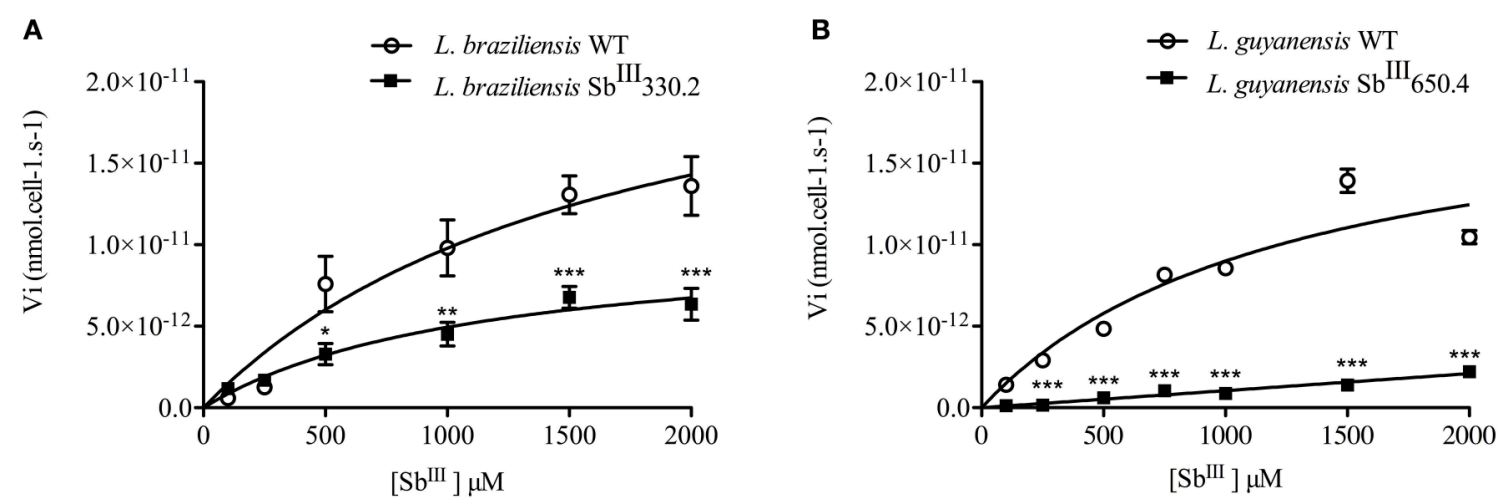

FIGURE 4 | Rate of Sb influx as a function of extracellular Sb concentration in WT and Sb ${ }^{\text {III }}$-resistant $L$. braziliensis $\mathbf{S b}{ }^{\text {III }} 330.2$ (A) and $L$. guyanensis $\mathrm{Sb}^{\mathrm{III}} 650.4$ (B). The parasites were exposed to different concentrations of Sblll for $1 \mathrm{~h}$ at $25^{\circ} \mathrm{C}$ in Hepes/NaCl/Glucose buffer and the intracellular Sb content was determined by graphite furnace atomic absorption spectroscopy. The influx rate of Sb was calculated as: Vi = amount of intracellular antimony/(number of cells $\mathrm{x}$ time of uptake). All experiments were performed at least three times as independent experiments in quadruplicate. The values are shown as means \pm SEM. Statistically different values are highlighted as ${ }^{*} p<0.05,{ }^{* *} p<0.01,{ }^{* *} p<0.001$.

(Essodaigui et al., 1999; Wesołowska, 2011; Rai et al., 2013) and BSO as intracellular thiol-depleting agent (Arana et al., 1998).

Table 5 displays the sensitivity $\left(\mathrm{IC}_{50}\right)$ of the L. braziliensis and L. guyanensis strains to the different ABC transporter inhibitors (See also growth inhibition curves in Supplementary Figure 3). Although most of the inhibitors exhibited $\mathrm{IC}_{50}$ values in the same range when comparing the WT and SbR strains, prochlorperazine showed a distinct profile, as it was about 20 -fold more active against the WT than LgSbR. This apparent crossresistance suggests that prochlorperazine and $\mathrm{Sb}^{\mathrm{III}}$ may share the same transport pathway in this mutant. Verapamil was also 2fold more active against the WT than LgSbR, however, it showed an opposite profile in the L. braziliensis strains.

The antileishmanial activities of $\mathrm{Sb}^{\mathrm{III}}$ in the absence and presence of $\mathrm{ABC}$ transporter inhibitors were compared, for each tested Leishmania strain (Table 6 See also growth inhibition curves in Supplementary Figures 4,5). Among the different inhibitors, prochlorperazine was the only agent to resensitize both SbR strains, the most pronounced effect being observed in L. guyanensis. Interestingly, no such sensitization was observed in the WT parental strains. However, the lower concentration of prochlorperazine used in the WT lines (because of their greater susceptibility) may explain the lack of sensitization. Probenecid specifically sensitized the L. braziliensis strains to $\mathrm{Sb}^{\mathrm{III}}$, but this effect occurred in both the mutant and wild-type strains. Surprisingly, verapamil promoted sensitization to $\mathrm{Sb}^{\mathrm{III}}$ specifically in the WT strains.

Figure 6 shows the impact of cell pre-exposure to $\mathrm{ABC}$ transporter inhibitors on the subsequent $\mathrm{Sb}$ uptake. Prochlorperazine was the only inhibitor to enhance Sb uptake specifically in SbR strains, in agreement with its sensitizing effect. On the other hand, probenecid enhanced the uptake of Sb 
only in LgSbR. It is noteworthy that BSO resulted in increased $\mathrm{Sb}$ uptake in LgSbR mutant and in both WT and LbSbR. In contrast, exposition to the metabolic inhibitor sodium azide did not promote significant change in Sb uptake in any of the tested cell lines. Also, corroborating the results of the sensitization assay, verapamil increased the Sb uptake in the WT strains of both species.

To evaluate the effect of the inhibitors on the efflux of Sb, cells were first exposed for $1 \mathrm{~h}$ to $1 \mathrm{mM} \mathrm{Sb}{ }^{\mathrm{III}}$, washed, resuspended in drug-free Hepes/ $\mathrm{NaCl}$ buffer and incubated for $2 \mathrm{~h}$ in the absence or presence of the inhibitor. Figure 7 displays the percentages of $\mathrm{Sb}$ released from the different strains after $2 \mathrm{~h}$ of efflux. Prochlorperazine was the only agent to significantly inhibit $\mathrm{Sb}$ efflux specifically in the resistant strains, in agreement with its ability to increase the cellular drug uptake. Probenecid reduced

TABLE 3 | Kinetic constants for Sb influx at $25^{\circ} \mathrm{C}$ in WT and Sb ${ }^{\text {III }}$-resistant $L$. braziliensis and $L$. guyanensis promastigotes.

\begin{tabular}{|c|c|c|c|c|}
\hline \multirow{2}{*}{$\begin{array}{l}\text { Leishmania } \\
\text { lines }\end{array}$} & \multicolumn{4}{|c|}{ INFLUX } \\
\hline & $\begin{array}{l}{ }^{{ }^{a}} K_{m} \\
(n M)\end{array}$ & $\begin{array}{c}{ }^{\mathrm{a}} \mathbf{V}_{\max } \\
\left(\mathrm{nmol} . \mathrm{s}^{-1} \cdot \text { cell }^{-1}\right)\end{array}$ & $\begin{array}{l}{ }^{b} \mathbf{k}_{\text {influx }} \\
\left(L . s^{-1} \cdot \text { cell }\right. \\
\end{array}$ & $\begin{array}{c}\mathbf{k}_{\text {influx }} \text { WT/ } \\
\text { k }_{\text {influx }} R\end{array}$ \\
\hline \multicolumn{5}{|c|}{ L. braziliensis } \\
\hline Wild-type & $1.7 \pm 1.0 \times 10^{6}$ & $2.6 \pm 0.2 \times 10^{-11}$ & $1.6 \times 10^{-17}$ & 1.8 \\
\hline Resistant & $1.1 \pm 0.6 \times 10^{6}$ & $1.1 \pm 0.1 \times 10^{-11}$ & $0.9 \times 10^{-17}$ & \\
\hline \multicolumn{5}{|c|}{ L. guyanensis } \\
\hline Wild-type & $1.3 \pm 0.3 \times 10^{6}$ & $2.0 \pm 0.1 \times 10^{-11}$ & $1.6 \times 10^{-17}$ & 166 \\
\hline Resistant & - & - & $0.1 \times 10^{-18}$ & \\
\hline
\end{tabular}

aThe values were obtained by nonlinear regression analysis according to the MichaelisMenten model.

${ }^{b}$ The values were calculated through $k_{\text {influx }}=V_{\max } / K_{m}$ (Michaelis-Menten model) or through $k_{\text {influx }}=$ Vi/Ce when no saturation was observed. the efflux of Sb in both mutants, but the effect was only significant in LbSbR. Sodium azide markedly inhibited the efflux of Sb mainly in SbR mutants, evidencing that Sb efflux in the resistant strains is essentially energy-dependent. The thiol-depleting agent BSO showed a significant effect only in LgSbR. On the other hand, verapamil exerted no significant effect on the drug efflux.

\section{DISCUSSION}

The main objective of the present work was to functionally characterize the transport routes of $\mathrm{Sb}$ in L. braziliensis and L. guyanensis strains selected for $\mathrm{Sb}$ resistance, by using systematic transport kinetic analysis and investigating the effect of ABC transporter inhibitors on uptake and efflux of Sb. This work can be seen as a continuation of a previous study performed on resistant laboratory mutants from the same Leishmania (Viannia) species, that also exhibited decreased influx and increased efflux of Sb (Moreira et al., 2013). New insights here include data on additional resistance markers such as mRNA levels of GSH1, LABCI4 and ARM58 and thiol levels, the demonstration of the energy-dependence of the efflux and the identification of a new chemosensitizer. In addition, the mutants studied here are different strains that were obtained independently in another laboratory. Indeed, our L. braziliensis mutant does not overexpress MRPA gene, contrary to the strain studied previously (Moreira et al., 2013).

The L. guyanensis mutant investigated previously showed down-regulation of AQP1 protein (Moreira et al., 2013), whereas the present mutant exhibits a single point mutation G133D in AQP1 (Monte-Neto et al., 2015). Functional validation confirmed that G133D mutation by itself is the main alteration related to reduced antimony uptake comparable
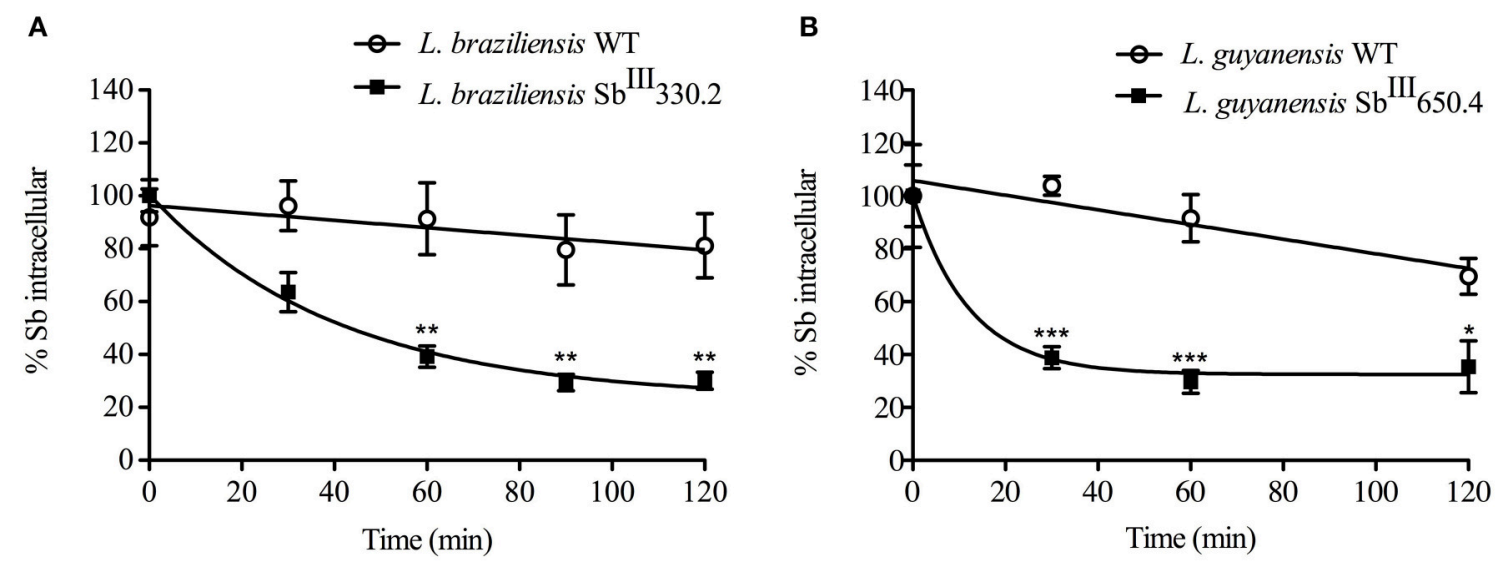

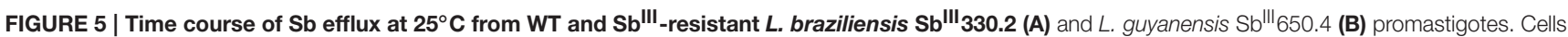
were first loaded for $1 \mathrm{~h}$ with $\mathrm{Sb}^{\mathrm{III}}$ and then washed, resuspended and incubated in drug-free Hepes/NaCl/Glucose buffer. After different time intervals (from 0 to 2 h), cells were retrieved and the amount of intracellular $\mathrm{Sb}$ was determined by graphite furnace atomic absorption spectroscopy. Data are expressed as percentage of initial Sb and shown as means \pm SEM. All experiments were carried out at least three times as independent experiments performed in quadruplicate. Statistically different values are highlighted as ${ }^{*} p<0.05,{ }^{* *} p<0.01,{ }^{* * *} p<0.001$. 
TABLE 4 | Kinetic constants for Sb ${ }^{\text {III }}$ efflux at $25^{\circ} \mathrm{C}$ in WT and $\mathrm{Sb}^{\mathrm{III}}$-resistant $L$. braziliensis and $L$. guyanensis promastigotes.

\begin{tabular}{|c|c|c|c|}
\hline \multirow[t]{2}{*}{ Leishmania lines } & \multicolumn{3}{|c|}{ EFFLUX } \\
\hline & ${ }^{a} k_{\text {efflux }}\left(L_{\text {L.s }}{ }^{-1} \cdot\right.$ cell $\left.^{-1}\right)$ & ${ }^{b} T_{1 / 2}(s)$ & $\mathrm{T}_{1 / 2} \mathrm{Wt} / \mathrm{T}_{1 / 2} \mathrm{R}$ \\
\hline \multicolumn{4}{|l|}{ L. braziliensis } \\
\hline Wild-type & $1.4 \times 10^{-17}$ & 593.5 & 21.0 \\
\hline Resistant & $8.6 \times 10^{-17}$ & 28.3 & \\
\hline \multicolumn{4}{|l|}{ L. guyanensis } \\
\hline Wild-type & $1.0 \times 10^{-17}$ & 379.8 & 45.0 \\
\hline Resistant & $13.7 \times 10^{-17}$ & 8.4 & \\
\hline
\end{tabular}

a The efflux rate constant $k_{\text {efflux }}$ was obtained from the equation: Ve $=k_{\text {efflux }} \times C i$, where $\mathrm{Ve}$ is the initial rate of efflux determined from the tangent of the kinetic curve and $\mathrm{Ci}$ is the intracellular concentration of Sb estimated at time zero using a cell volume of $1.2 \times$ $10^{-14} \mathrm{~L}$.

${ }^{b}$ The half-time of Sb efflux ( $\left.T_{1 / 2}\right)$ was calculated using mono-exponential decay model.

with levels observed in L. guyanensis lacking AQP1 (MonteNeto et al., 2015). Since AQP1 also plays an important role in osmoregulation (Figarella et al., 2007), when submitted to a hypoosmotic challenge, L. guyanensis SbR mutants increased volume and presented a delayed recovery time compared to their WT counterpart, a profile that was also comparable with AQP1 lacking L. guyanensis, confirming the highly destabilizing nature of G133D mutation for AQP1 (R. Monte-Neto and D. Pires, unpublished results). The increased mRNA levels of MRPA and the marked reduction of $\mathrm{Sb}$ influx, as reported here, are consistent the previously reported amplification of the MRPA gene and the mutated and inactivated form of AQP1 (Monte-Neto et al., 2015).

Interestingly, the L. braziliensis SbR mutant did not show significant change in the mRNA levels of either MRPA, LABCI4, or ARM58 (Figure 1), suggesting that these transport proteins are not involved in the resistance mechanism of this strain. The lack of important change in antimony uptake in LbSbR mutant is in agreement with the unchanged AQP1 mRNA levels (Figure 1) together with the fact that gene sequence is intact (Supplementary Figure 1). Examining clinical isolates of $L$. braziliensis from brazilian patients presenting different antimonial treatment outcomes, Torres et al. (2010) did not find any difference in the expression levels of antimony metabolism associated genes such as MRPA, AQP1, GSH1, GSH2, TRYR, and TDR1 (Torres et al., 2010). It is noteworthy to mention that the resistance index (RI) of 7-fold presented by LbSbR (Table 2) is comparable with clinical isolates (Pérez et al., 2016) in which mechanisms of resistance would differ from those obtained from other laboratory-selected mutants presenting higher resistance indexes, like LgSbR that is approximately 25 times more resistant to Sb than its WT counterpart (Table 2). Indeed, laboratoryselected L. braziliensis presenting antimony RI of 20-fold had increased MRPA-encoding mRNA levels (Moreira et al., 2013), confirming the multifactorial nature of $\mathrm{Sb}$ resistance, being the mechanisms dependent on the RI.

Although no significant change was observed in mRNA levels of GSH1 and ODC, increased levels of the intracellular thiols cysteine and glutathione were found in LgSbR, while LbSbR presented higher contents of trypanothione, when
TABLE 5 | Sensitivity $\left(\mathrm{IC}_{50} \pm \mathrm{SEM}\right)$ of $L$. braziliensis and $L$. guyanensis strains to different $A B C$ transporter inhibitors (verapamil, probenicid, prochlorperazine, BSO).

\begin{tabular}{|c|c|c|c|c|}
\hline \multirow{3}{*}{$\begin{array}{l}\text { Transporter } \\
\text { inhibitors }\end{array}$} & \multicolumn{4}{|c|}{$\mathrm{IC}_{50} \pm \mathrm{SEM}$} \\
\hline & \multicolumn{2}{|c|}{ L. braziliensis } & \multicolumn{2}{|c|}{ L. guyanensis } \\
\hline & Wild-type & Resistant & Wild-type & Resistant \\
\hline Verapamil ( $\mu \mathrm{M})$ & $63.8 \pm 1.8$ & $27.0 \pm 0.1$ & $45.6 \pm 3.4$ & $82.7 \pm 0.1$ \\
\hline Prochlorperazine $(\mu \mathrm{M})$ & $7.5 \pm 2.3$ & $11.6 \pm 0.1$ & $3.5 \pm 0.6$ & $68.4 \pm 0.1$ \\
\hline Probenecid (mM) & $204.5 \pm 1.2$ & $101.0 \pm 0.2$ & $503.5 \pm 3.3$ & $385.3 \pm 31.5$ \\
\hline $\mathrm{BSO}(\mathrm{mM})$ & $>100$ & $>100$ & $>100$ & $53.4 \pm 0.8$ \\
\hline
\end{tabular}

TABLE 6 | Effect of different ABC transporter inhibitors ${ }^{a}$ on the half-maximal growth inhibition concentration $\left(\mathrm{IC}_{50}\right)$ of $\mathrm{Sb}^{\mathrm{III}}$ in Sb-resistant $L$. braziliensis and $L$. guyanensis promastigotes and their respective parental lines.

\begin{tabular}{|c|c|c|c|c|}
\hline \multirow{3}{*}{$\begin{array}{l}\text { Transporter } \\
\text { inhibitors }\end{array}$} & \multicolumn{4}{|c|}{ IC50 of SbIII \pm SEM $(\mu M)$} \\
\hline & \multicolumn{2}{|c|}{ L. braziliensis } & \multicolumn{2}{|c|}{ L. guyanensis } \\
\hline & Wild-type & Resistant & Wild-type & Resistant \\
\hline $\mathrm{Sb}^{111}$ & $86.1 \pm 1.1$ & $623.7 \pm 44.7$ & $47.4 \pm 7.8$ & $1167 \pm 1.1$ \\
\hline Verapamil & $23.5 \pm 3.5^{\star \star}$ & $402.7 \pm 18.2$ & $9.5 \pm 0.3^{\star \star}$ & $877.7 \pm 1.2$ \\
\hline Prochlorperazine & $78.0 \pm 3.7$ & $332.2 \pm 17.4^{*}$ & $68.6 \pm 1.4$ & $146.4 \pm 1.3^{\star \star \star}$ \\
\hline Probenecid & $45.7 \pm 2.3^{\star}$ & $330.0 \pm 45.5^{\star}$ & $51.9 \pm 1.2$ & $1163.4 \pm 1.2$ \\
\hline BSO & $75.5 \pm 3.0$ & $567.8 \pm 4.6$ & $43.0 \pm 4.5$ & $945.3 \pm 5.7$ \\
\hline
\end{tabular}

${ }^{a}$ Non-toxic concentrations were used: $8 \mu \mathrm{M}$ verapamil, $4 \mathrm{mM}$ probenecid, $10 \mu \mathrm{M}$ prochlorperazine, $100 \mu \mathrm{MBSO}$ in resistant strains and $8 \mu \mathrm{M}$ verapamil, $4 \mathrm{mM}$ probenecid, $3.5 \mu \mathrm{M}$ prochlorperazine, $100 \mu \mathrm{M}$ BSO in parental strains.

${ }^{*} p<0.05,{ }^{* *} p<0.01,{ }^{* * *} p<0.001$ for statistical comparison to treatment with $S b^{\text {III }}$ alone. The data comes from at least three independent experiments.

compared with their WT counterparts (Figure 2). A similar LgSbR thiol profile including increased levels of cysteine and glutathione without trypanothione change was also observed in SbR L. donovani field isolates (Mukherjee et al., 2007) and could be explained by a positive feedback where alterations in two thiol biosynthetic steps enhanced the amount of reduced trypanothione that can be depleted by a Sb-dependent mechanisms like Sb-TSH conjugate efflux (Wyllie et al., 2004). However, LbSbR presented an opposite profile, having higher trypanothione level and equivalent amounts of cysteine and glutathione, when compared with WT (Figure 2). Romero et al. (2015) reported an increase in total intracellular thiol content of $L$. braziliensis upon overexpression of cysteine synthase and cystathionine- $\beta$-synthase in presence of oxidative and nitrosative stresses (Romero et al., 2015). Thus, overexpression of other thiol biosynthetic enzyme(s) probably contributes to antimony resistance phenotype in our mutant. The increased amount of total intracellular thiols in absence of GSH1 mRNA alterations as reported here was previously reported in clinical isolates of SbR L. donovani (Rai et al., 2013), also supporting the fact that the involvement of thiol metabolism in laboratory-selected SbR Leishmania (Viannia) species is a feature shared with field isolates. 

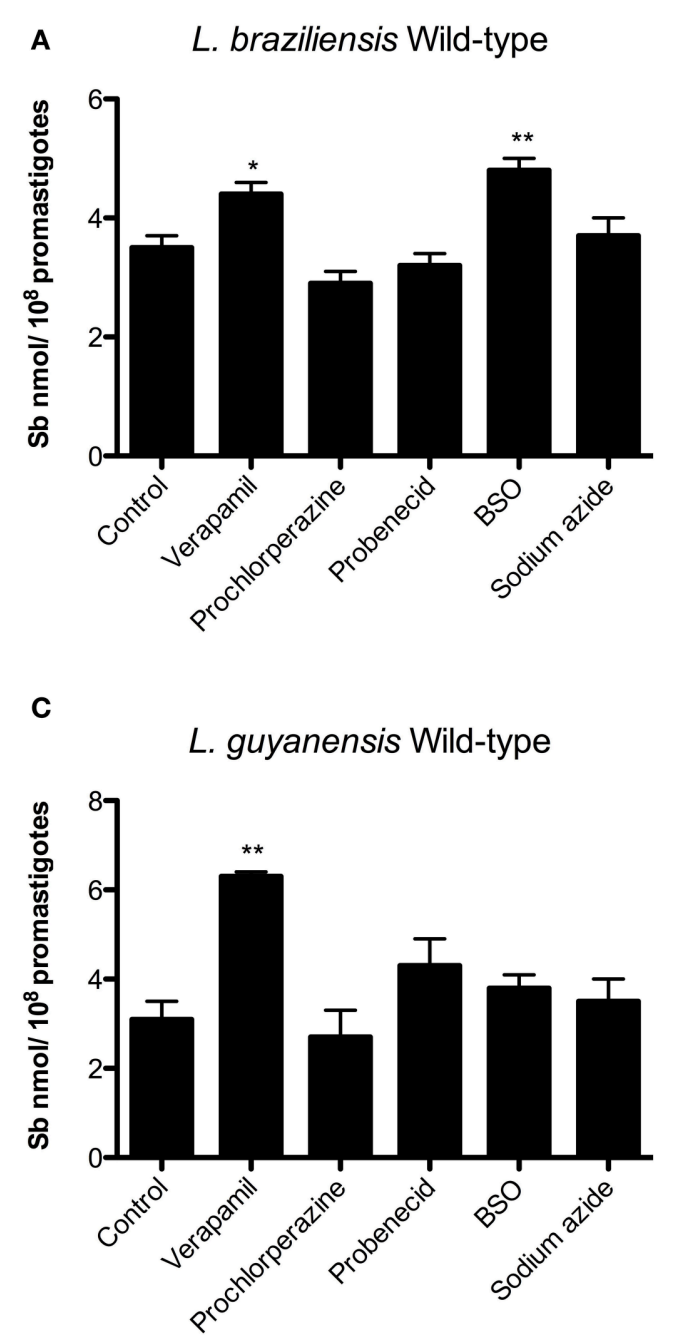

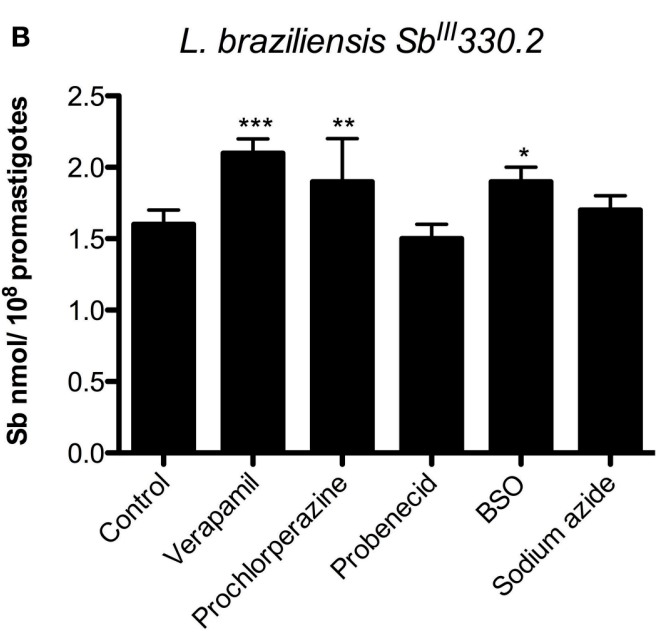

D

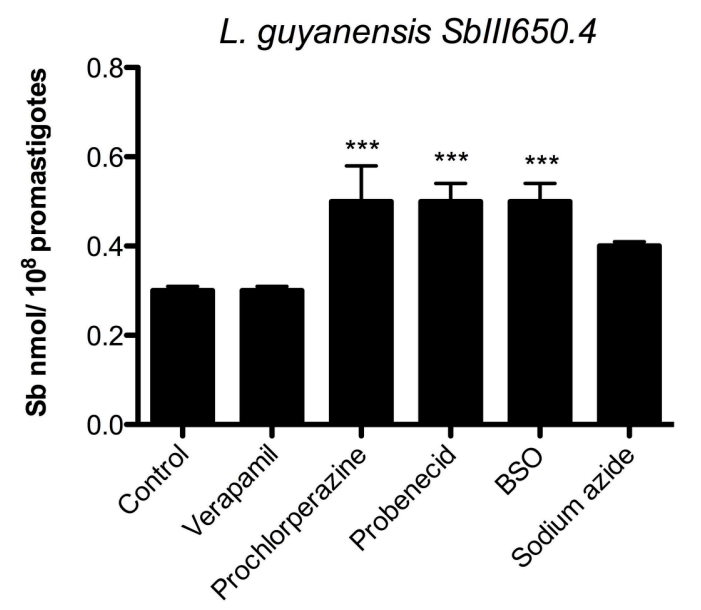

FIGURE 6 | Effect of pre-exposure to different ABC transporter inhibitors on Sb uptake in WT (A) and Sb ${ }^{I I I}$-resistant (B) L. braziliensis and WT (C) and $\mathrm{Sb}^{\mathrm{III}}$-resistant (D) L. guyanensis promastigotes. The cells were pre-incubated for $24 \mathrm{~h}$ in $\alpha$-MEM in the absence or presence of the inhibitor ( $8 \mu \mathrm{M}$ verapamil, $4 \mathrm{mM}$ probenecid, $10 \mu \mathrm{M}$ prochlorperazine, $100 \mu \mathrm{M}$ BSO in resistant strains and $8 \mu \mathrm{M}$ verapamil, $4 \mathrm{mM}$ probenecid, $3.5 \mu \mathrm{M}$ prochlorperazine, $100 \mu \mathrm{M}$ BSO in parental strains), then exposed to $1 \mathrm{mM} \mathrm{Sb}{ }^{\mathrm{III}}$ for $1 \mathrm{~h}$ in $\mathrm{HG}$ buffer, washed and processed to determine the intracellular Sb content. When evaluating sodium azide, the cells were resuspended in glucose-free HG buffer containing $10 \mathrm{mM}$ azide and $1 \mathrm{mM} \mathrm{Sb}{ }^{\mathrm{III}}$ and incubated for $1 \mathrm{~h}$. The data comes from at least three independent experiments and are shown as means \pm SEM. ${ }^{\star} p<0.05,{ }^{\star \star} p<0.01,{ }^{\star \star \star} p<0.001$ for statistical comparison to Control, using One-way ANOVA followed by Bonferroni multiple comparison test.

From the transport kinetic studies, it is clear that both influx and efflux pathways contributed to the reduced cellular accumulation of $\mathrm{Sb}$ and the drug resistance phenotype. However, the change in drug influx had a much greater contribution in the L. guyanensis than in the L. braziliensis mutant. The fact that influx was not saturable in LgSbR, in contrast to the other strains, suggests that $\mathrm{Sb}^{\mathrm{III}}$ enters into this cell through an AQP1-independent non-saturable transport route. A strongly energy-dependent efflux was clearly evidenced in both mutants. In LgSbR, the marked effect of BSO on Sb efflux (Figure 7) and the influence of probenecid on Sb uptake (Figure 6) further support the involvement of a MRP-type transporter capable of extruding metal-thiol conjugates. This transporter may be functionally related to MRPA found to be overexpressed in this mutant. Interestingly, the increased levels of thiols and MRPA mRNA in LgSbR also correlates with its higher sensitivity to BSO compared to its WT counterpart, in agreement with the observation of Moreira et al. (2013) for L. braziliensis. Whether the efflux transport also involves an exocytosis or a secretion pathway, as previously hypothesized (Legaré et al., 2001; Manzano et al., 2013; Perea et al., 2016; Tejera Nevado et al., 2016), still need to be investigated. In LbSbR, the effect of probenecid on the Sb efflux is also consistent with a MRP-type transporter, however, no increase in gene expression of the potential transporters MRPA, LABCI4 and ARM58 was observed (Figure 1). The lack of effect of BSO 
A

L. braziliensis Wild-type

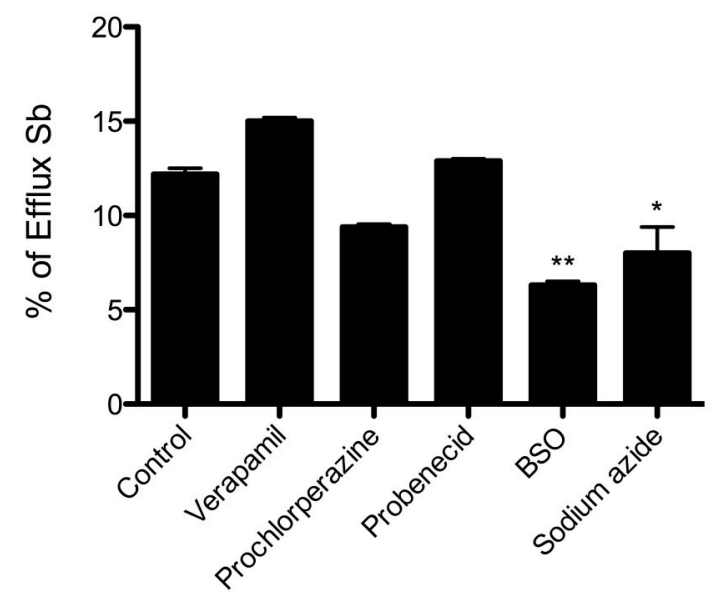

C

\section{L. guyanensis Wild-type}

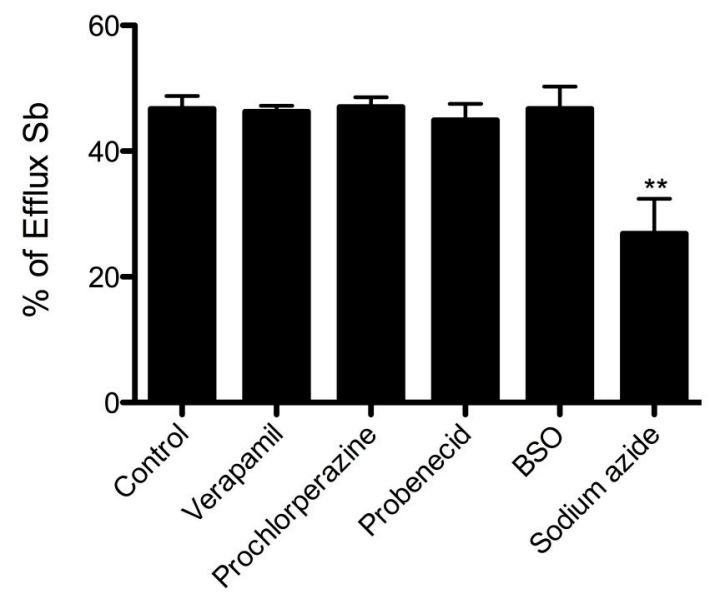

B

L. braziliensis $S b^{\prime \prime \prime} 330.2$

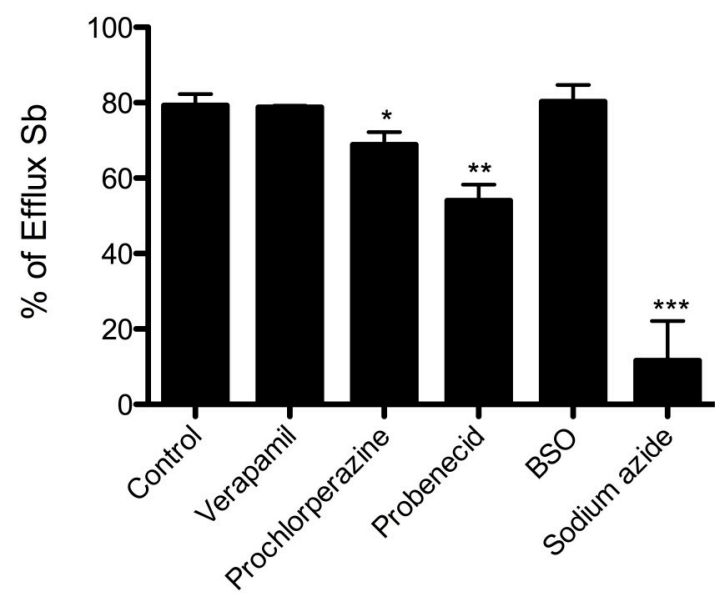

D

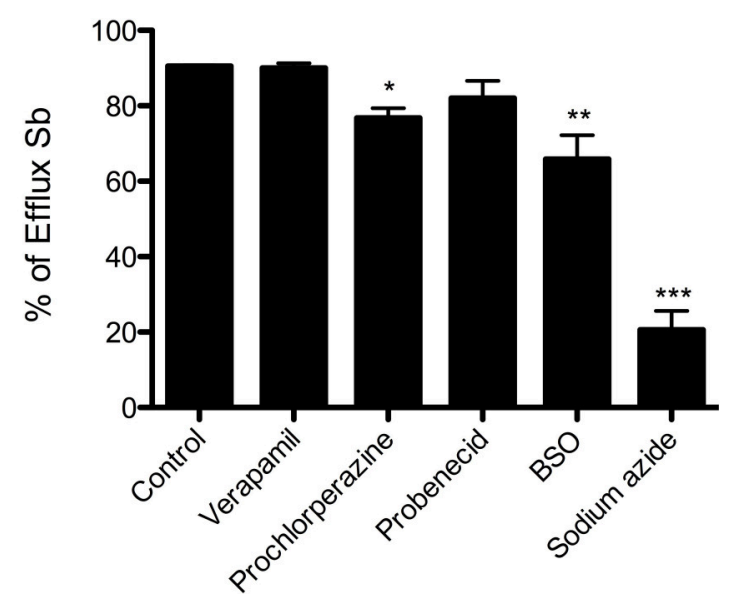

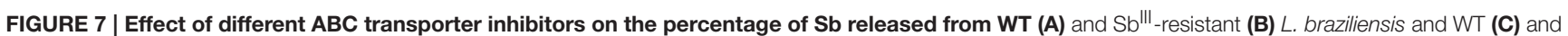
$\mathrm{Sb}^{\mathrm{III}}$-resistant (D) $\mathrm{L}$. guyanensis promastigotes, after $2 \mathrm{~h}$ of efflux. Cells were first exposed for $1 \mathrm{~h}$ at $25^{\circ} \mathrm{C}$ to $1 \mathrm{mM} \mathrm{Sb}{ }^{\mathrm{III}}$, were washed and resuspended in $\mathrm{HG}$ buffer at $108 \mathrm{cell} / \mathrm{sL}$ and were incubated for $2 \mathrm{~h}$ at $25^{\circ} \mathrm{C}$ in the absence or presence of the inhibitor $(8 \mu \mathrm{M}$ verapamil, $4 \mathrm{mM}$ probenecid, $10 \mu \mathrm{M}$ prochlorperazine, $100 \mu \mathrm{M}$ BSO, $10 \mathrm{mM}$ sodium azide in resistant strains and $8 \mu \mathrm{M}$ verapamil, $4 \mathrm{mM}$ probenecid, $3.5 \mu \mathrm{M}$ prochlorperazine, $100 \mu \mathrm{M}$ BSO, $10 \mathrm{mM}$ sodium azide in parental strains). Only when evaluating the effect of azide, that the buffer did not contain glucose. The cells were finally washed and processed to determine the cellular content of $\mathrm{Sb}$. The data are shown as the percentage of $\mathrm{Sb}$ released for $2 \mathrm{~h}$ in relation to the initial cellulart $\mathrm{Sb}$ content. The data comes from at least three independent experiments and are shown as means \pm SEM. ${ }^{\star} p<0.05,{ }^{\star \star} p<0.01,{ }^{\star \star *} p<0.001$ for statistical comparison to Control (without inhibitor), using One-way ANOVA followed by Bonferroni multiple comparison test.

(Figure 7) also suggests no apparent dependence of the efflux on thiol, even though trypanothione showed higher levels in this mutant.

Verapamil significantly enhanced the sensitivity to $\mathrm{Sb}^{\mathrm{III}}$ in the WT cell lines, but not in the mutants. In the parental cells, it also increased the uptake of $\mathrm{Sb}$. On the other hand, no effect on $\mathrm{Sb}$ efflux was observed. Since verapamil was reported to inhibit the ABC transporter PRP1 in L. major, which was also found to confer low level of resistance to $\mathrm{Sb}^{\mathrm{III}}$ (Coelho et al., 2003), a possible participation of PRP1 in the transport of $\mathrm{Sb}^{\mathrm{III}}$ in the wild-type cells can be suggested.

The ability of prochlorperazine to specifically sensitize the resistant strains to $\mathrm{Sb}^{\mathrm{III}}$ and inhibit the active efflux of $\mathrm{Sb}$ is an important finding of the present work. Due to its higher cytotoxicity toward WT than SbR strains, prochlorperazine was tested at lower concentration in the sensitization and transport assays of the WT strains. This may also explain the lack of effect of this drug in the WT strains. Our data strongly supports the model that this compound sensitizes the mutants to Sb by inhibiting 
the efflux route of $\mathrm{Sb}$. However, one cannot completely discard the possibility that the sensitizing effect of prochlorperazine may come from the combined toxic effects of prochlorperazine and $\mathrm{Sb}^{\mathrm{III}}$. Nevertheless, the efflux data in the resistant mutants which were co-exposed to prochlorperazine and $\mathrm{Sb}^{\mathrm{III}}$ for only $2 \mathrm{~h}$, strongly support a direct effect of prochlorperazine on efflux pathway. The lack of combined toxic effects is also reinforced by the fact that the WT strains which were more sensitive to both $\mathrm{Sb}^{\mathrm{III}}$ and prochlorperazine did not exhibit any sensitizing effects. Prochlorperazine belongs to the class of phenothiazine drugs which have been found to be effective inhibitors of MDR1transporters in cancer cells (Wesołowska, 2011; Takács et al., 2015). In Leishmania, these compounds were also reported to inhibit the efflux pumps of fluorescent substrates of $\mathrm{ABC}$ transporters (Essodaigui et al., 1999; Rai et al., 2013). However, it is the first report of a phenothiazine derivative capable of overcoming the antimony resistance in Leishmania parasites by interfering in the drug efflux. Regarding the mechanism of action of this compound, it may act either by competing with $\mathrm{Sb}^{\mathrm{III}}$ for efflux transport or by reducing the intracellular concentration of reduced thiol through inhibition of the trypanothione reductase (Chan et al., 1998). The fact that prochlorperazine and Sb ${ }^{\mathrm{II}}$ showed cross-resistance in the L. guyanensis mutant (Table 5) supports the idea that these drugs may share the same transport pathway and is consistent with the competition transport model.

In conclusion, the present study allowed the biophysical and pharmacological characterization of energy-dependent $\mathrm{Sb}$ efflux pathway apparently independent of MRPA, ABCI4, and ARM58 upregulation, in a Leishmania (Vianna) mutant selected in vitro for resistance to $\mathrm{Sb}^{\mathrm{III}}$. Prochlorperazine has also been identified as an effective chemosensitizer in both $\mathrm{Sb}$ resistant mutants, which acts through inhibition of the active efflux of Sb.

\section{REFERENCES}

Alvar, J., Velez, I. D., Bern, C., Herrero, M., Desjeux, P., Cano, J., et al. (2012). Leishmaniasis worldwide and global estimates of its incidence. PLoS ONE 7:e35671. doi: 10.1371/journal.pone.0035671

Arana, F. E., Pérez-Victoria, J. M., Repetto, Y., Morello, A., Castanys, S., and Gamarro, F. (1998). Involvement of thiol metabolism in resistance to glucantime in Leishmania tropica. Biochem. Pharmacol. 56, 1201-1208. doi: 10.1016/S0006-2952(98)00129-4

Berg, M., Vanaerschot, M., Jankevics, A., Cuypers, B., Maes, I., Mukherjee, S., et al. (2013). Metabolic adaptations of Leishmania donovani in relation to differentiation, drug resistance, and drug pressure. Mol. Microbiol. 90, 428-442. doi: $10.1111 / \mathrm{mmi} .12374$

Bradford, M. (1976). A rapid and sensitive method for the quantification of microgram quantities of protein utilizing the principle of protein-dye binding assay. Anal. Biochem. 72, 248-254. doi: 10.1016/0003-2697(76)90527-3

Brochu, C., Wang, J., Roy, G., Messier, N., Wang, X. Y., Saravia, N. G., et al. (2003). Antimony uptake systems in the protozoan parasite leishmania and accumulation differences in antimony-resistant parasites. Antimicrob. Agents Chemother. 47, 3073-3079. doi: 10.1128/AAC.47.10.3073-3079.2003

Callahan, H. L., Roberts, W. L., Rainey, P. M., and Beverley, S. M. (1994). The PGPA gene of Leishmania major mediates antimony $\left[\mathrm{Sb}^{\mathrm{III}}\right]$ resistance by decreasing influx and not by increasing efflux. Mol. Biochem. Parasitol. 68, 145-149. doi: 10.1016/0166-6851(94)00154-5

Chan, C., Yin, H., Garforth, J., McKie, J. H., Jaouhari, R., Speers, P., et al. (1998). Phenothiazine inhibitors of trypanothione reductase as potential

\section{AUTHOR CONTRIBUTIONS}

PR performed the influx and efflux experiments and biological assays e wrote the first draft of the manuscript. RM selected the L. braziliensis and L. guyanensis mutants, performed the uptake experiment and qRT-PCR analysis and revised the manuscript. MM designed the biological assays and revised the manuscript. FF designed the whole study with emphasis on the transport experiments and wrote the final version of the manuscript.

\section{FUNDING}

This work was supported by the Brazilian agencies Coordenação de Aperfeiçoamento de Pessoal de Nível Superior (2447/09), Conselho Nacional de Desenvolvimento Científico e Tecnológico (303227/2013-3), Fundação de Amparo à Pesquisa do Estado de Minas Gerais (CBB - APQ-01542-13 and RED-00007-14).

\section{ACKNOWLEDGMENTS}

The authors would like to specially thank Nayara Kesia Lima Mendes Moura for technical support. We thank Prof. Marc Ouellette at CHU de Québec, Université Laval, Québec, QC, Canada, for the valuable collaboration on thiol measurements. We also thank Gaétan Roy for his technical support on thiol separation by HPLC.

\section{SUPPLEMENTARY MATERIAL}

The Supplementary Material for this article can be found online at: http://journal.frontiersin.org/article/10.3389/fcell. 2017.00024/full\#supplementary-material

antitrypanosomal and antileishmanial drugs. J. Med. Chem. 41, 148-156. doi: $10.1021 / \mathrm{jm} 960814 \mathrm{j}$

Cheng, T. F., and Sun, H. Z. (2014). "Chap 25. Antimony and bismuth," in Binding, Transport, and Storage of Metal Ions in Biological Cells, eds A. G. Wedd and W. Maret (London, UK: The Royal Society of Chemistry), 768-799.

Coelho, A. C., Beverley, S. M., and Cotrim, P. C. (2003). Functional genetic identification of PRP1, an ABC transporter superfamily member conferring pentamidine resistance in Leishmania major. Mol. Biochem. 30, 83-90. doi: 10.1016/s0166-6851(03)00162-2

Courtois, A., Payen, L., Lagadic, D., Guillouzo, A., and Fardel, O. (1999). Evidence for a multidrug resistance-associated protein 1 (MRP1)-related transport system in cultured rat liver biliary epithelial cells. Life Sci. 64, 763-774. doi: 10.1016/S0024-3205(98)00618-3

Croft, S. L., Sundar, S., and Fairlamb, A. H. (2006). Drug resistance in leishmaniasis. Clin. Microbiol. Rev. 19, 111-126. doi: 10.1128/CMR.19.1.111126.2006

Decuypere, S., Rijal, S., Yardley, V., De Doncker, S., Laurent, T., Khanal, B., et al. (2005). Gene expression analysis of the mechanism of natural $\mathrm{Sb}(\mathrm{V})$ resistance in Leishmania donovani isolates from Nepal. Antimicrob. Agents Chemother. 49, 4616-4621. doi: 10.1128/AAC.49.11.4616-4621.2005

Decuypere, S., Vanaerschot, M., Brunker, K., Imamura, H., Müller, S., Khanal, B., et al. (2012). Molecular mechanisms of drug resistance in natural Leishmania populations vary with genetic background. PLoS Negl. Trop. Dis. 6:e1514. doi: 10.1371/journal.pntd.0001514

Dey, S., Papadopoulou, B., Haimeur, A., Roy, G., Grondin, K., Dou, D., et al. (1994). High level arsenite resistance in Leishmania tarentolae is 
mediated by an active extrusion system. Mol. Biochem. Parasitol. 67, 49-57. doi: 10.1016/0166-6851(94)90095-7

Do Monte-Neto, R. L., Coelho, A. C., Raymond, F., Légaré, D., Corbeil, J., Melo, M. N., et al. (2011). Gene expression profiling and molecular characterization of antimony resistance in Leishmania amazonensis. PLoS Negl. Trop. Dis. 5:e1167. doi: 10.1371/journal.pntd.0001167

Essodaigui, M., Frézard, F., Moreira, E. S. A., Dagger, F., and Garnier-Suillerot, A. (1999). Energy-dependent efflux from Leishmania promastigotes of substrates of the mammalian multidrug resistance pumps. Mol. Biochem. Parasitol. 100, 73-84. doi: 10.1016/S0166-6851(99)00036-5

Fairlamb, A. H., Henderson, G. B., Bacchi, C. J., and Cerami, A. (1987). In vivo effects of difluoromethylornithine on trypanothione and polyamine levels in bloodstream forms of Trypanosoma brucei. Mol. Biochem. Parasitol. 24, 185-191. doi: 10.1016/0166-6851(87)90105-8

Figarella, K., Uzcategui, N. L., Zhou, Y., LeFurgey, A., Ouellette, M., Bhattacharjee, H., et al. (2007). Biochemical characterization of Leishmania major aquaglyceroporin LmAQP1: possible role in volume regulation and osmotaxis. Mol. Microbiol. 65, 1006-1017. doi: 10.1111/j.1365-2958.2007.05845.x

Freshney, R. I. (1994). Culture of Animal Cells: A Manual of Basic Technique. New York, NY: Wiley-Liss Publishers.

Frézard, F., Demicheli, C., and Ribeiro, R. R. (2009). Pentavalent antimonials: new perspectives for old drugs. Molecules 14, 2317-2336. doi: 10.3390/molecules 14072317

Frézard, F., Monte-Neto, R., and Reis, P. G. (2014). Antimony transport mechanisms in resistant leishmania parasites. Biophys. Rev. 6, 119-132. doi: 10.1007/s12551-013-0134-y

Fumarola, L., Spinelli, R., and Brandonisio, O. (2004). In vitro assays for evaluation of drug activity against Leishmania spp. Res. Microbiol. 155, 224-230. doi: 10.1016/j.resmic.2004.01.001

Gazanion, É., Fernández-Prada, C., Papadopoulou, B., Leprohon, P., and Ouellette, M. (2016). Cos-Seq for high-throughput identification of drug target and resistance mechanisms in the protozoan parasite Leishmania. Proc. Natl. Acad. Sci. U.S.A. 113, E3012-E3021. doi: 10.1073/pnas.1520693113

Hadighi, R., Mohebali, M., Boucher, P., Hajjaran, H., Khamesipour, A., and Ouellette, M. (2006). Unresponsiveness to Glucantime treatment in Iranian cutaneous leishmaniasis due to drug-resistant Leishmania tropica parasites. PLoS Med. 3:e162. doi: 10.1371/journal.pmed.0030162

Kazemi-Rad, E., Mohebali, M., Khadem-Erfan, M. B., Saffari, M., Raoofian, R., Hajjaran, H., et al. (2013). Identification of antimony resistance markers in Leishmania tropica field isolates through a cDNA-AFLP approach. Exp. Parasitol. 135, 344-349. doi: 10.1016/j.exppara.2013.07.018

Kumar, D., Singh, R., Bhandari, V., Kulshrestha, A., Negi, N. S., and Salotra, P. (2012). Biomarkers of antimony resistance: need for expression analysis of multiple genes to distinguish resistance phenotype in clinical isolates of Leishmania donovani. Parasitol. Res. 111, 223-230. doi: 10.1007/s00436-012-2823-z

Legaré, D., Richard, D., Mukhopadhyay, R., Stierhof, Y. D., Rosen, B. P., Haimeur, A., et al. (2001). The Leishmania ATP-binding cassette protein PGPA is an intracellular metal-thiol transporter ATPase. J. Biol. Chem. 276, 26301-26307. doi: 10.1074/jbc.M102351200

Lira, R., Sundar, S., Makharia, A., Kenney, R., Gam, A., Saraiva, E., et al. (1999). Evidence that incidence of treatment failure in Indian kala-azar is due to the emergence of antimony resistant strains of Leishmania donovani. J. Infect. Dis. 180, 564-567. doi: 10.1086/314896

Mandal, G., Sarkar, A., Saha, P., Singh, N., Sundar, S., and Chartterjee, M. (2009). Functionality of drug efflux pumps in antimonial resistant Leishmania donovani field isolates. Indian J. Biochem. Biophys. 46, 86-92. Available online at: http://nopr.niscair.res.in/handle/123456789/3322

Manzano, J. I., Garcia-Hernandez, R., Castanys, S., and Gamarro, F. (2013). A new $\mathrm{ABC}$ half-transporter in Leishmania is involved in resistance to antimony. Antimicrob. Agents Chemother. 57, 3719-3730. doi: 10.1128/AAC.00211-13

Marquis, N., Gourbal, B., Rosen, B. P., Mukhopadhyay, R., and Ouellette, M. (2005). Modulation in aquaglyceroporin AQP1 gene transcript levels in drug-resistant Leishmania. Mol. Microbiol. 57, 1690-1699. doi: 10.1111/j.1365-2958.2005.04782.x

Marzochi, M. C., and Marzochi, K. B. (1994). Tegumentary and visceral leishmaniases in Brazil: emerging anthropozoonosis and possibilities for their control. Cad. Saude Publica 10, 2359-2375. doi: 10.1590/s0102-311x1994000800014

Monte-Neto, R., Laffitte, M. C., Leprohon, P., Reis, P. G., Frézard, F., and Ouellette, M. (2015). Intrachromosomal amplification, locus deletion and point mutation in the aquaglyceroporin AQP1 gene in antimony resistant Leishmania (Viannia) guyanensis. PLoS Negl. Trop. Dis. 9:e0003476. doi: 10.1371/journal.pntd.0003476

Moreira, D. S., Monte-Neto, R. L., Andrade, J. M., Santi, A. M. M., Reis, P. G., Frézard, F., et al. (2013). Molecular characterization of the MRPA transporter and antimony uptake in four New World Leishmania spp. susceptible and resistant to antimony. Int. J. Parasitol. Drugs Drug Resist. 3, 143-153. doi: 10.1016/j.ijpddr.2013.08.001

Mukherjee, A., Padmanabhan, P. K., Singh, S., Roy, G., Girard, I., Chatterjee, M., et al. (2007). Role of ABC transporter MRPA, gamma-glutamylcysteine synthetase and ornithine decarboxylase in natural antimony-resistant isolates of Leishmania donovani. J. Antimicrob. Chemother. 59, 204-211. doi: $10.1093 / \mathrm{jac} / \mathrm{dkl} 494$

Mukhopadhyay, R., Dey, S., Xu, N., Gage, D., Lightbody, J., Ouellette, M., et al. (1996). Trypanothione overproduction and resistance to antimonials and arsenicals in Leishmania. Proc. Natl. Acad. Sci. U.S.A. 93, 10383-10387. doi: 10.1073/pnas.93.19.10383

Murray, H. W., Berman, J. D., Davies, C. R., and Saravia, N. G. (2005). Advances in leishmaniasis. Lancet 366, 1561-1577. doi: 10.1016/S0140-6736(05)67629-5

Neal, R. A., Van Bueren, J., McCoy, N. G., and Iwobi, M. (1989). Reversal of drug resistance in Trypanosoma cruzi and Leishmania donovani by verapamil. Trans. R. Soc. Trop. Med. Hyg. 83, 197-198. doi: 10.1016/0035-9203(89)90642-1

Nühs, A., Schäfer, C., Zander, D., Trübe, L., Tejera Nevado, P., Schmidt, S., et al. (2013). A novel marker, ARM58, confers antimony resistance to Leishmania spp. Int. J. Parasitol. Drugs Drug Resist. 4, 37-47. doi: 10.1016/j.ijpddr.2013.11.004

Ouellette, M., Drummelsmith, J., and Papadopoulou, B. (2004). Leishmaniasis: drugs in the clinic, resistance and new developments. Drug Resist. Updat. 7, 257-266. doi: 10.1016/j.drup.2004.07.002

Papadopoulou, B., Roy, G., Dey, S., Rosen, B. P., and Ouellette, M. (1994). Contribution of the Leishmania P-glycoprotein-related gene ltpgpA to oxyanion resistance. J. Biol. Chem. 269, 11980-11986.

Payen, L., Courtois, A., Campion, J. P., Guillouzo, A., and Fardel, O. (2000). Characterization and inhibition by a wide range of xenobiotics of organic anion excretion by primary human hepatocytes. Biochem. Pharmacol. 60, 1967-1975. doi: 10.1016/S0006-2952(00)00496-2

Perea, A., Manzano, J. I., Castanys, S., and Gamarro, F. (2016). The LABCG2 transporter from the protozoan parasite Leishmania is involved in antimony resistance. Antimicrob. Agents Chemother. 60, 3489-3496. doi: 10.1128/AAC.02813-15

Pérez, V. G., García-Hernandez, R., Corpas-López, V., Tomás, A. M., MartínSanchez, J., Castanys, S., et al. (2016). Decreased antimony uptake and overexpression of genes of thiol metabolism are associated with drug resistance in a canine isolate of Leishmania infantum. Int. J. Parasitol. Drugs Drug Resist. 6, 133-139. doi: 10.1016/j.ijpddr.2016.04.003

Perry, M. R., Wyllie, S., Prajapati, V. K., Feldmann, J., Sundar, S., Boelaert, M., et al. (2011). Visceral leishmaniasis and arsenic: an ancient poison contributing to antimonial treatment failure in the Indian subcontinent? PLoS Negl. Trop. Dis. 5:e1227. doi: 10.1371/journal.pntd.0001227

Rai, S., Bhaskar, G. S. K., Nath Dwivedi, U., Sundar, S., and Goyal, N. (2013). Role of efflux pumps and intracellular thiols in natural antimony resistant isolates of Leishmania donovani. PLoS ONE 8:e74862. doi: 10.1371/journal.pone.00 74862

Roberts, W. L., and Rainey, P. M. (1993). Antileishmanial activity of sodium stibogluconate fractions. Antimicrob. Agents Chemother. 37, 1842-1846. doi: 10.1128/AAC.37.9.1842

Romero, I., Téllez, J., Romanha, A. J., Steindel, M., and Grisard, E. C. (2015). Upregulation of cysteine and cystathionine- $\beta$-synthase contributes to Leishmania brasiliensis survival under oxidative stress. Antimicrob. Agents Chemother. 59, 4770-4781. doi: 10.1128/AAC.04880-14

Schäfer, C., Tejera Nevado, P., Zander, D., and Clos, J. (2014). Reduced antimony accumulation in ARM58-overexpressing Leishmania infantum. Antimicrob. Agents Chemother. 58, 1565-1574. doi: 10.1128/AAC.01881-13 
Takács, D., Csonka, Á., Horváth, Á., Windt, T., Gajdács, M., Riedl, Z., et al. (2015). Reversal of ABCB1-related multidrug resistance of colonic adenocarcinoma cells by phenothiazines. Anticancer Res. 35, 3245-3251. Available online at: http://ar.iiarjournals.org/content/35/6/3245.short

Tejera Nevado, P., Bifeld, E., Höhn, K., and Clos, J. (2016). A telomeric cluster of antimony resistance genes on chromosome 34 of Leishmania infantum. Antimicrob. Agents Chemother. 60, 5262-5275. doi: 10.1128/AAC.00544-16

Torres, D. C., Adaui, V., Ribeiro-Alves, M., Romero, G. A., Arévalo, J., Cupolillo, E., et al. (2010). Targeted gene expression profiling in Leishmania brasiliensis and Leishmania guyanensis parasites isolated from brazilian patients with different antimonial treatment outcomes. Infect. Genet. Evol. 10, 727-733. doi: 10.1016/j.meegid.2010.05.006

Valiathan, R., Dubey, M. L., Mahajan, R. C., and Malla, N. (2006). Leishmania donovani: effect of verapamil on in vitro susceptibility of promastigote and amastigote stages of Indian clinical isolates to sodium stibogluconate. Exp. Parasitol. 114, 103-108. doi: 10.1016/j.exppara.2006. 02.015

Wesołowska, O. (2011). Interaction of phenothiazines, stilbenes and flavonoids with multidrug resistance-associated transporters, P-glycoprotein and MRP1.
Acta Biochim. Pol. 58, 433-448. Available online at: http://www.actabp.pl/pdf/ 4_2011/433.pdf

Wyllie, S., Cunningham, M. L., and Fairlamb, A. H. (2004). Dual action of antimonial drugs on thiol redox metabolism in human pathogen Leishmania donovani. J. Biol. Chem. 279, 39925-39932. doi: 10.1074/jbc.M405635200

Zilberstein, D., and Dwyer, D. M. (1984). Glucose transport in Leishmania donovani promastigotes. Mol. Biochem. Parasitol. 12, 327-336. doi: 10.1016/0166-6851(84)90089-6

Conflict of Interest Statement: The authors declare that the research was conducted in the absence of any commercial or financial relationships that could be construed as a potential conflict of interest.

Copyright (C) 2017 Reis, Monte-Neto, Melo and Frézard. This is an open-access article distributed under the terms of the Creative Commons Attribution License (CC BY). The use, distribution or reproduction in other forums is permitted, provided the original author(s) or licensor are credited and that the original publication in this journal is cited, in accordance with accepted academic practice. No use, distribution or reproduction is permitted which does not comply with these terms. 